\title{
Humidification strategy for polymer electrolyte membrane fuel cells
}

\author{
- A review \\ Yafei Chang, ${ }^{\mathrm{a}}$ Yanzhou Qin ${ }^{\mathrm{a}}$, Yan Yin ${ }^{\mathrm{a}^{*}}$, Junfeng Zhang ${ }^{\mathrm{a}}$, Xianguo $\mathrm{Li}^{\mathrm{a} *}$ \\ ${ }^{a}$ State Key Laboratory of Engines, Tianjin University, 135 Yaguan Road, Tianjin 300350, \\ China \\ ${ }^{\mathrm{b}}$ Department of Mechanical and Mechatronics Engineering, University of Waterloo, Waterloo, \\ ON, Canada \\ *Corresponding authors: yanyin@tju.edu.cn; x6li@uwaterloo.ca
}

Abstract: Polymer electrolyte membrane fuel cells are promising power sources because of their advantage such as high efficiency, zero emission and low operating temperature. Water management is one of the critical issues for polymer electrolyte membrane fuel cells and has received significant attention. The membrane within the cells needs to stay in hydrated state to have high ion conductivity and durability, which requires proper humidification. Both internal and external methods have been utilized to humidify the polymer electrolyte membrane. Numerous studies on fuel cell humidification have been conducted in the past decades, especially in recent years. This review aims to summarize the main humidification methods and the related studies. The internal humidification methods are classified as physical methods and chemical methods. The external humidification methods include gas bubbling humidification, direct water injection, enthalpy wheel humidification, membrane humidifiers, and exhaust gas recirculation. The working principle and performance of 
each method are introduced and the advantages and drawbacks are summarized. Further, the humidification methods for alkaline anion exchange membrane fuel cells are also briefly reviewed, because of more recent studies showing their potential of using non-precious metal catalysts. This review can help to choose proper humidification strategy for specific polymer electrolyte membrane fuel cell application and may inspire further investigations.

Keywords: Polymer electrolyte membrane fuel cell; Humidification; Water management; External; Internal.

\section{Nomenclature}

$\begin{array}{ll}A & \text { membrane area, } \mathrm{m}^{2} \\ n \& & \text { mass flow rate, } \mathrm{kg} \mathrm{s}^{-1} \\ P & \text { pressure, } \mathrm{Pa} \\ x & \text { molar fraction }\end{array}$

Greek letters

$\lambda \quad$ stoichiometry ratio

Superscripts and subscripts

air cathode inlet air

DI dry side inlet

DO dry side outlet

$\mathrm{H}_{2} \mathrm{O} \quad$ water (liquid/vapor) 
outlet cathode outlet

sat saturation

Abbreviations

1D one dimensional

AEMFC alkaline anion exchange membrane fuel cell

CFD computational fluid dynamics

CL catalyst layer

DMFC direct methanol fuel cell

GDL gas diffusion layer

MCFC molten carbonate fuel cell

MEA membrane electrode assembly

PAFC phosphoric acid fuel cell

PEMFC polymer electrolyte membrane fuel cell

PFSA perfluorosulfonic acid

PSU polysulfone

PTFE polytetrafluoroethylene

RH relative humidity

SOFC solid oxide fuel cell

WRR water recovery ratio

WTR water transfer rate

\section{Contents}




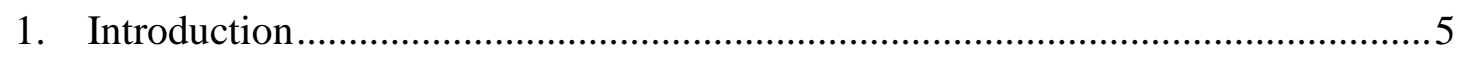

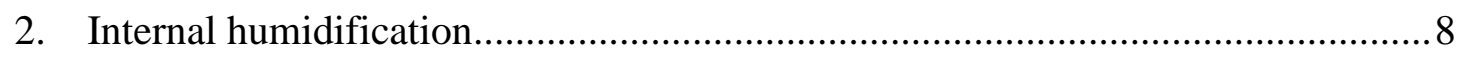

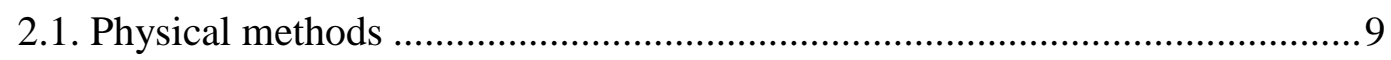

2.1.1. Changing the physical structure..................................................... 9

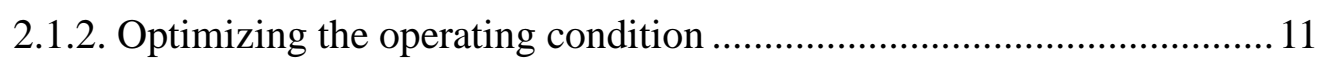

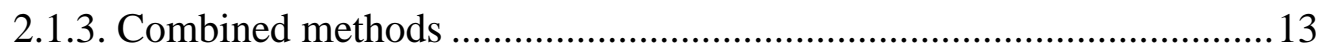

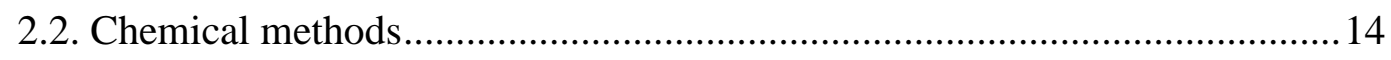

2.2.1. Changing the composition of membrane ......................................... 14

2.2.2. Changing the composition of electrode ........................................... 18

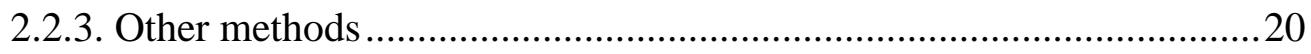

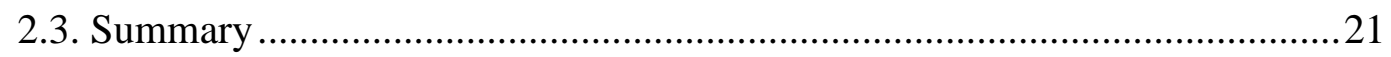

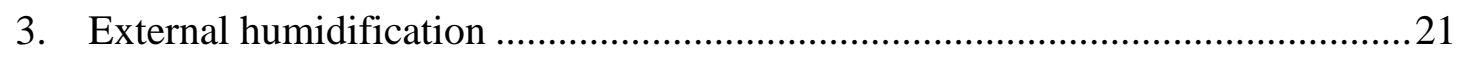

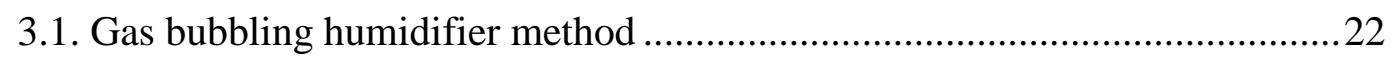

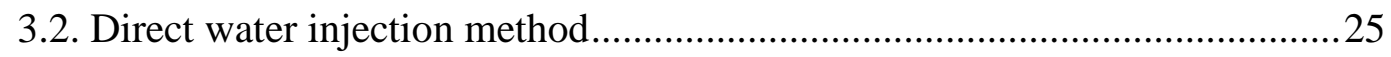

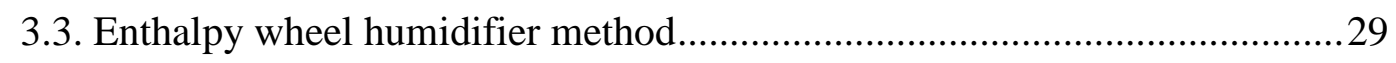

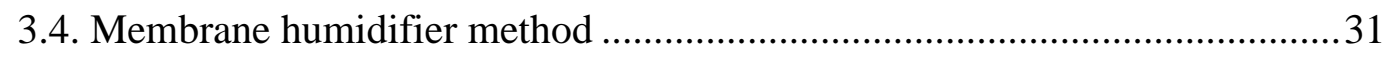

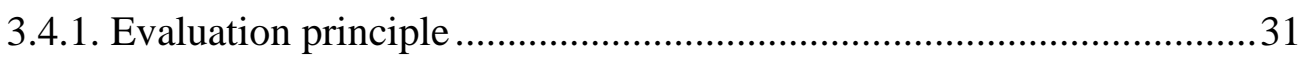

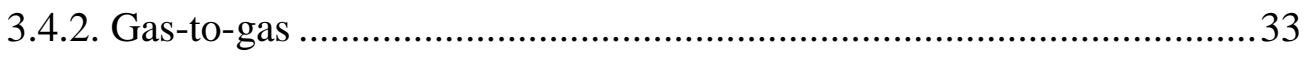

3.4.2.1. Flow direction arrangement ................................................ 34

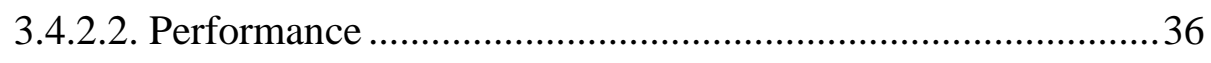

3.4.2.3. Improvement methods ....................................................... 38

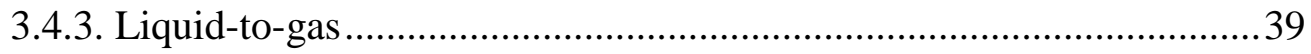


3.6. Summary 43

4. Humidification for alkaline anion exchange membrane fuel cells 44

5. Conclusions and directions for the future research

References 48

\section{Introduction}

Fuel cell is one of the most promising energy conversion devices which can convert chemical energy of the fuel (such as hydrogen) to electrical energy directly with high efficiency and zero pollution. It has consequently received increasing attention in recent years due to increasing concerns and awareness in the supply and use of primary energy, environmental protection and energy sustainability.

There are many different types of fuel cells according to the different electrolytes and fuels used, such as polymer electrolyte membrane fuel cell (PEMFC), direct methanol fuel cell (DMFC), solid oxide fuel cell (SOFC), molten carbonate fuel cell (MCFC), phosphoric acid fuel cell (PAFC), alkaline fuel cell (AFC), and alkaline anion exchange membrane fuel cell (AEMFC) [1]. Among all these types, PEMFC is regarded as the most promising alternative power source for automotive application owing to the advantage of low noise, low operating temperature and high power density [2]. It is also suitable for residential power generation since both heat and power can be utilized simultaneously with high efficiency [3]. In addition, PEMFC 
may be used for portable applications such as electronic devices, owing to its high energy capability [4]. The schematic of a PEMFC is shown in Fig. 1. It mainly consists of bipolar plate, gas diffusion layer (GDL), catalyst layer (CL) and polymer electrolyte membrane (PEM). Hydrogen is supplied to the anode while air (or oxygen) is supplied to the cathode. Reactant gases flow through the GDLs, then electrochemical reactions occur in the CLs. The only by-product is water, thus the fuel cell is quite environmentally friendly.

Despite the advantages mentioned above, technical challenges such as water management remain to be resolved, hindering the performance improvement and commercialization of fuel cells. Water management has been regarded as one of the critical issues for practical PEMFCs [2]. The membrane needs to maintain sufficient hydration level to conduct protons efficiently. In addition, low humidification or non-humidification operation may accelerate the membrane degradation process due to the radical formation [5] and membrane dehydration [6]. However, too much water may result into the phenomenon known as water flooding in the porous electrode structures which may impede the reactants transport. Thus the amount and distribution of water within the fuel cell structure need to be optimized in order to achieve high conductivity and durability of the proton-conducting membrane while facilitating the transport of reactants.

In order to investigate techniques for the water management and humidification of 
PEMFCs, different methods have been proposed such as adding microporous layers [7], improving the GDL pore structure [8], and designing novel flow field structure [9]. The membrane is originally in dry state and needs to be supplied with water during operation. Internal or external humidification methods are adopted to humidify the membrane in most cases. The internal humidification methods are classified as physical methods and chemical methods in this paper according to the principles of operation involved. The external humidification methods include gas bubbling humidification, direct water (liquid/vapor) injection, enthalpy wheel humidifiers, membrane humidification, and exhaust gas recirculation. Humidification system is an important auxiliary system for PEMFC which may influence the performance and durability of the fuel cell. It is of great importance to choose proper humidification strategy for different applications. For example, for portable or vehicle applications, internal humidification may be preferable to reduce weight and space; while for stationary applications, sufficient humidification performance becomes more important, thus gas bubbling humidification or direct water injection method is more preferable. In order to choose proper humidification strategy, it is necessary to understand the characteristics and research techniques for each humidification strategy. Actually, plenty of work has been done comprehensively in recent years. However, very few relevant literature review about this topic has been published.

Thus the objective of this paper is to review the published studies on the internal and external humidification methods for PEMFCs. The advantages and disadvantages of 
each method are summarized and recommendations are given for practical applications. Furthermore, AEMFCs have been drawing much attention in recent years because of the possibility of using non-precious catalyst in alkaline environment [10]. Water management for AEMFCs shares much similarity to PEMFCs, although they also have their uniqueness which results from the different electro-chemical reactions involved. Thus challenges to the water management and humidification for AEMFCs are also briefly described.

This review is organized as follow. Internal humidification methods are presented in Section 2. Internal humidification is classified as physical methods and chemical methods, which will be given in Section 2.1 and 2.2 separately. External humidification methods are reviewed in Section 3 including gas bubbling humidification, direct water (liquid/vapor) injection, enthalpy wheel humidifiers, membrane humidification and exhaust gas recirculation. Humidification for AEMFCs is provided in Section 4, emphasizing the difference from and similarity to PEMFCs. Finally, the conclusions and directions for future research are given in Section 5.

\section{Internal humidification}

The internal humidification methods aim to maintain the membrane in a hydrated state by changing the internal PEMFC structure or composition without adopting external devices. According to the different water management strategies, internal humidification methods are classified as physical methods and chemical methods in 
this review.

\subsection{Physical methods}

Internal humidification can be achieved by physical methods like changing the physical structure or optimizing the operating condition. These two methods can also be combined to achieve better performance.

\subsubsection{Changing the physical structure}

PEMFCs produce water as a by-product through electrochemical reaction. However, the produced water distributes unevenly within the electrode. Water flooding may occur in some parts (like the region near the flow channel outlet) while other parts (like the region near the flow channel inlet) may be in dry condition. Therefore, humidification can be achieved by redistributing the water produced by the electrochemical reaction. To achieve this goal, special channels are often considered. Qi and Kaufman [11] designed a kind of new flow channels that have two gas inlets and two gas outlets as shown in Fig. 2(a). The inlet of one flow channel is situated adjacent to the outlet of the other flow channel. Thus the dry gas entering the channel is humidified by moist gas exiting the adjacent channel, allowing the membrane and catalyst layers to be hydrated effectively without external humidification. However, the inlet gas of one channel may flow directly to the outlet of the other channel, which may cause gas leakage. This problem need to be reduced by taking some special measures. Belchor et al. [12] designed a parallel serpentine-baffle flow field as shown 
in Fig. 2(b), which can mitigate water loss from channels. This design permits the fuel cell to operate with low water content at higher temperature. However, flooding will occur when the fuel cell is operated at low temperature or high humidification level, thus the application range of the fuel cell is restricted.

Besides the design of new flow field layouts, new cell components may be added to retain water. Ge et al. [13] mounted two sponge wicks between the membrane electrode assembly (MEA) and cathode flow channel as shown in Fig. 3. The sponge can absorb the produced water and then transfer the moist to the inlet dry air, thus it is helpful for both inlet air humidification and liquid water removal.

A novel humidification concept is developed through separating the membrane into an active area and a humidification area [14]. In this design, the fresh gas flows into the humidification section first and the exhaust gas from the reaction section also flows into the humidification section to humidify the fresh gas. Water can be transferred through the membrane. A similar concept was also investigated by Wang et al. [15] who surrounded the active electrode region with an inactive "water transfer region" as shown in Fig. 4. In this design, the produced water in the cathode can be transferred across the membrane to the anode to humidify the hydrogen. This method is attractive because of its relatively good performance; however, the incorporation of the "water transfer region” increases the total volume of the cell, which is less favorable for mobile applications. 
These methods humidify the reactant gas or membrane through changing the fuel cell physical structure, and are passive in the operation. There is no need for additional equipment and no parasitic energy is consumed. However, proper water management can only be achieved under restricted operating conditions [16]. And also, the humidification performance is less effective than the external humidification methods [17].

\subsubsection{Optimizing the operating condition}

Proper operating regime has been sought where PEMFCs can operate without any humidification. It is found that, without humidification, the fuel cell performance depends strongly on the operating temperature, stoichiometry ratio, and pressure gradient between the anode and the cathode [16,18-21]. Based on a mathematical model, Chan et al. [18] found that at low current density $\left(0.1 \mathrm{~A} \mathrm{~cm}^{-2}\right)$, water tends to flow from the cathode to the anode due to the pressure gradient between them, thus water need to be supplied to the cathode. Nevertheless, in the case of relatively high

current density $\left(0.4 \mathrm{~A} \mathrm{~cm}^{-2}\right)$, water tends to move from the anode to the cathode because the electro-osmotic drag effect is dominant over the pressure effect, thus the anode needs to be humidified. However, they proposed that there exists a current density between 0.1 and $0.4 \mathrm{~A} \mathrm{~cm}^{-2}$ at which the electro-osmotic drag effect and the pressure effect can reach a balance, and thus the fuel cell can operate without external humidification. Noponen et al. [19] investigated the effect of operating temperature 
on a free-breathing PEMFC with dry hydrogen supply. They concluded that the optimum operating temperature was around $60{ }^{\circ} \mathrm{C}$ for their fuel cell considering the effect of mass transport and water evaporation. Their conclusion agrees well with the experimental results conducted by Martin et al. [20].

Actually, at a specific operating temperature, the relative humidity $(\mathrm{RH})$ at the cathode outlet is highly dependent on the air/oxygen stoichiometry. Assuming that all the water produced by the cathode electrochemical reaction is exhausted to the cathode outlet with the air flow, the relationship between the air stoichiometry $\left(\lambda_{\text {air }}\right)$ and the $\mathrm{RH}$ at the cathode outlet can be expressed as [20]:

$$
\lambda_{\text {air }}=x_{\mathrm{O}_{2}}\left[\frac{2 P_{\text {outlet }}}{P_{\text {sat }}} \frac{100}{R H_{\text {outlet }}}-1\right]
$$

where $x_{\mathrm{O}_{2}}$ is the molar fraction of oxygen at the cathode inlet, $P_{\text {outlet }}$ is the cathode outlet pressure, $R H_{\text {outlet }}$ is the relative humidity of cathode outlet (expressed as a percentage), and $P_{\text {sat }}$ is the saturated vapor pressure at the specific temperature. For different temperature, the saturated vapor pressure is different, influencing the relationship between $\lambda_{\text {air }}$ and $R H_{\text {outlet }}$, as plotted in Fig. 5. It indicates that higher operating temperature leads to lower $\mathrm{RH}$ at the same air stoichiometry ratio. Decreasing the air stoichiometry ratio can help to increase the $\mathrm{RH}$; however, the cathode may suffer oxidant starvation. Based on the similar principle, Riascos et al. [16] designed a control technique which can maintain the $\mathrm{RH}$ at a desirable value for various operating conditions by adjusting the air stoichiometry. Further, Williams et al. 
[21] conducted an overall analysis comparing the efficiency of PEMFCs with dry and wet operation. It was found that under the optimized operating parameters (operating temperature and air stoichiometry) with dry operation, the net power output was reduced by no more than $17 \%$ in comparison with the commercial MEAs operated at fully humidified condition. In spite of the reduced power output, the parasitic loss induced by the humidifiers and condensers was also cut by over $46 \%$. Therefore it is possible to run the fuel cell under dry condition with acceptable overall system performance. However, this method is not practical because the operating parameters must be controlled within a very narrow range with a relatively low current density.

The fuel cell durability without humidification can also be improved by adjusting the operating condition and $\mathrm{Pt} / \mathrm{C}$ ratio. Long term tests of 1000 hour at dry operation were carried out by Martin et al. [20]. The air stoichiometry ratio is optimized ( $\lambda_{\text {air }}=8$ ) and the highest steady-state voltage is $611 \mathrm{mV}$ with a current density of $200 \mathrm{~mA} \mathrm{~cm}^{-2}$. The specific parameters and operating conditions are available in [20].

\subsubsection{Combined methods}

Toyota launched their fuel cell vehicle "Mirai" in 2014 [22]. High performance is achieved owing to the innovative flow structure and MEA [23]. Toyota Mirai adopts an internal humidification system which is one of its main innovations [24]. Their internal humidification system combines the effects of stack structure improvement and operating condition optimization [25], as shown in Fig. 6. On the aspects of stack 
structure improvement, three methods are used to uniformly distribute the water without external humidification. First, the membrane thickness is reduced to promote the water back-diffusion from the cathode. Second, the hydrogen and air streams are arranged to flow in counter directions thus the moisture near the anode outlet can be used to humidify the cathode inlet gas. Moreover, the temperature is controlled by adjusting the coolant flow to prevent water evaporation from the membrane. On the aspects of operating conditions optimization, the hydrogen recirculation rate can be adjusted according to different operating conditions to effectively utilize the back-diffusion water from the cathode. In addition, changing the anode inlet pressure might be helpful to enhance the evaporation and transfer of the generated water to the anode surfaces. By applying these methods, the fuel cell stack can maintain good performance without an external humidifier.

\subsection{Chemical methods}

Different from the physical methods which maintain the membrane in hydrated state by humidifying the reactant gases, the chemical methods directly reserve water inside the MEA by changing the composition of membrane or electrode, which will be discussed respectively.

\subsubsection{Changing the composition of membrane}

Gas crossover is a common phenomenon in PEMs because polymeric membranes exhibit some gas diffusivity and permeability. Thus, through incorporating the 
membrane with some additives, reactant gases that permeate into the membrane may interact with the incorporated additives to produce water. Normally the additive consists of catalyst and water retention materials like $\mathrm{SiO}_{2}$ or $\mathrm{TiO}_{2}$. The schematic of the humidification mechanism is shown in Fig. 7. Water is produced through the reaction of permeated gases with catalyst and the produced water can be retained by hygroscopic additives in the membrane. This method is also called "self-humidification" in many studies [26-29]. Thus the chemical internal humidification methods are described in the name of "self-humidification" in the subsequent section in order to keep consistent with literatures.

As early as in 1990s, Watanabe and co-workers investigated the self-humidification of PEMFCs using PEMs incorporating $\mathrm{Pt}$ and $\mathrm{SiO}_{2}$ or $\mathrm{TiO}_{2}$ [26-28]. As mentioned above, the reaction of permeated hydrogen and oxygen is catalyzed by the platinum particles to generate water, which in turn is adsorbed and retained by the oxide particles. The fuel cell displayed stable and high performance even under ambient pressure with fully humidified hydrogen at $20{ }^{\circ} \mathrm{C}$ and dry oxygen [26]. Through measuring the amount of exhausted water from both anode and cathode, they found that the water produced by the permeated gases inside the membrane was exhausted from the anode [27]. Moreover, the addition of $\mathrm{TiO}_{2}$ enhances the back-diffusion of water that generated by the electrochemical reaction from the cathode to the anode, owing to the hygroscopic property of $\mathrm{TiO}_{2}$ [28]. Thus the membrane at the anode side that dried by the electro-osmotic drag can be humidified effectively. Since it has been 
shown that the fuel cell performance can be improved clearly after adding Pt into the membrane, Kwak et al. [29] further investigated the effect of Pt loading on the self-humidifying membrane and reported that the optimum Pt loading was $0.15 \mathrm{mg}$ $\mathrm{cm}^{-2}$ in their study.

Despite the performance improvements of the self-humidification method, the presence of Pt particles incorporated within the membrane increases the risk of electrical short circuit due to hot spots within the fuel cell [30]. In addition, it is difficult to control the amount and dispersion of Pt in the membrane [31]. In order to solve these problems, Yang et al. [30] fabricated a membrane with a sandwich structure instead of the previous design (uniform Pt distribution as shown in Fig.8 (a)). Their concepts are shown in Fig. 8 (b). In their design, the membrane is split into two layers with one layer of Pt particles lying between them. The electron transport path is cut off through this design. Similar concept was also adopted by Liu et al. [31] and Yang et al. [32]. However, this method causes another problem: the Pt particles layer brings more resistance to the proton transfer. Wang et al. [33] deposited the Pt particle with a gradient distribution as shown in Fig. 8 (c). This design is a compromise of the previous two structures which prevent the electron transfer through the membrane and meanwhile has low resistance for proton transfer.

Besides the Pt additives mentioned above, some other materials have been investigated to achieve internal humidification [34-45]. The additives investigated 
subsequently and their advantages are listed in Table 1. In addition, novel composite membranes based on electrospun polymers combined with doped protic plastic crystals have been developed for the PEMFC operation without humidification [46]. Recently, the study conducted by Cha et al. [47] shows that short-side-chain membrane exhibits better reliability and higher water retention ability than long-side-chain membrane, which implies the potential to use short-side-chain membrane under low humidity.

Although the advantages of the composite membranes are observed to be significant, issues are still yet to be addressed. On one hand, the formation of electron conducting path is still a concern because the Pt particle can migrate inside the membrane after long run. On the other hand, the hygroscopic oxides embedded into the membrane may decrease the durability of the membrane because of the local stress change around the particles [48]. Moreover, the additives may decrease the toughness of the membrane which accelerates the fuel crossover [49].

Park et al. [50] recently provided a new concept which might keep the capability of water retention without changing the membrane structure. They deposited a hydrophobic layer on the surface of the membrane by atmospheric plasma treatment. Nano-cracks form on the coating layer when the membrane is exposed under higher humidity environment, allowing water migration. As shown in Fig. 9, the formed cracks expand when humidity is high but shrink under low humidification, thus water 
can be retained inside the membrane to achieve high ionic conductivity. It is reported that the power density of the coated PEMs can be up to four times larger than the un-coated ones at both high temperature and low $\mathrm{RH}$ conditions. Their efforts contribute to an insight into correlation between polymer structure and water/ion transport [51].

\subsubsection{Changing the composition of electrode}

In PEMFCs, CLs also contain ionomer serving as the binder and conducting medium for proton from the reaction site to the membrane. Excepting the dehydration of membrane, the ionomer binder in the CLs may also lose water at high temperature which may increase the resistance to proton conduction. Thus based on the concept of adding additives into the membrane to retain water, it is necessary to prepare composite CLs with water retention particles to maintain the CL proton conductivity at high temperature operating condition.

Vengatesan et al. [35,52] added $\mathrm{SiO}_{2}$ to both CLs and membrane to achieve self-humidification and high proton conductivity. It is found that the addition of small amount of $\mathrm{SiO}_{2}$ in the cathode CL improve the cell performance significantly at high temperature operation. However, the addition in the anode CL may decrease the fuel cell performance at high temperature due to the reduction of electro osmotic drag process. Han et al. [53] adopted a conventional hydrophobic electrode with $\mathrm{SiO}_{2} /$ Nafion suspension to achieve self-humidification. It is shown that the optimal 
$\mathrm{SiO}_{2} / \mathrm{Nafion}$ weight percentage is $6 \%$ at $60{ }^{\circ} \mathrm{C}$ without external humidification.

Even though the water retention capacity of $\mathrm{SiO}_{2}$ has been proved, the oxide particles may migrate to other locations which lowers the fuel cell performance in the long term. To improve the CL stability, the amorphous $\mathrm{SiO}_{2}$ was immobilized on the carbon surface in the study of Su et al. [49]. An 80h long term test was conducted which confirms the high performance of their composite catalyst.

Based on the similar principle, some other additives have also been used to support the Pt particle and achieve self-humidification [48,49,54-62]. The advantages and the related references are listed in Table 2. Besides, Koh et al. [63] reported a dual-layered electrode consist of a nano-sized dense-structure layer coated on the normal catalyst layer. The additional layer had water retention ability owing to the highly twisted pore structure which makes the water movement pathway much longer. This study provides a new approach to retain water by adjusting the pore structure, rather than adding water retention materials.

In addition to the CLs, the water retained in the GDLs can also help to improve the PEMFC performance under non-humidification condition. It is found that the liquid water distribution is highly dependent on the hydrophilicity of the GDLs. With different polytetrafluoroethylene (PTFE) content, the liquid water volume fraction inside the GDL varied from 0.15 to 0.62 as reported by Park et. al [64]. Fig. 10 shows 
the optical microscopy images of the GDL. The PEMFC was operated at a cell voltage of $0.6 \mathrm{~V}$ without humidification. Sample (a) was not treated with PTFE loading while sample (b) was coated with a PTFE loading of 5\%. Water condensed on the GDL surface as shown in Fig. 10. It can be found that water streams form in Fig. 10 (a), meanwhile only water droplets are observed in Fig. 10 (b). They explained that this may result from the heterogeneous condensation caused by the defects on the GDL surface. However, the PTFE fills in the surface defects and increases the hydrophobicity of the GDL which prevents the capillary condensation. In addition, their numerical results show that the optimum water saturation at the GDL surface is between 0.1 and 0.3 under non-humidification condition which compromise the species diffusivity and proton conductivity.

\subsubsection{Other methods}

Besides adding additives to the membrane or electrodes, some other methods that change the MEA structure or improve the MEA preparation process can also be used to achieve self-humidification. For example, Kong et al. [65,66] enhanced the self-humidification by adopting double gas diffusion backing layers. Recently, Breitwieser et al. [67] fabricated a PEMFC with direct membrane deposition [68] which facilitates the back diffusion from the cathode to the anode. The neutron radiography test was carried out and it is shown that the humidification level of the MEA stay constant even with dry anode and low cathode RH (15\%). 
The group of Xiang et al. [69] recently exploited a new concept of "bipolar membranes" to humidify the membrane by the water from electrochemical reaction. In this design, the membrane consists of two parts: an acidic membrane on the anode and an alkaline membrane on the cathode, as shown in Fig. 11. Water is generated at the interface of the acidic membrane and alkaline membrane. Then the generated water diffuses to both anode and cathode to humidify the membrane on both sides. This concept can achieve passive self-humidification over the entire cell. Moreover, the alkaline cathode has faster kinetics which allows a reduction in the Pt loading or even the use of non-Pt catalyst. They further developed a mathematical model to instruct the design of the "bipolar membranes" fuel cell [70].

\subsection{Summary}

For the internal humidification methods, external devices are not necessary, hence saving the system volume and weight. It is very attractive for compact applications like portable and mobile devices and automobiles. However, the physical methods result into complicated design. For the chemical methods, the durability and stability of the fuel cell still need further investigation and validation. In addition, both methods can only be used for low power or portable PEMFC applications [54]. The application for high power devices still needs further optimization.

\section{External humidification}

The external humidification aims to humidify the reactant gases before entering into 
the fuel cell. In this section, the working principles of the typical external humidification methods are reviewed, including gas bubbling humidifier method, direct water injection method, enthalpy wheel humidifier method, membrane humidifier method and exhaust gas recirculation method.

\subsection{Gas bubbling humidifier method}

The gas bubbling humidifier method is commonly used to humidify the inlet gas. In the gas bubbling humidifier, reactant gas stream flows through a tube into the bottom of a container filled with heated water as shown in Fig. 12. The gas is dispersed to a lot of small bubbles and then flows out from the water. In some cases, the bottom can be filled with some glass beads which can provide sufficient contact area that can ensure the gas can be fully humidified.

Although this method is commonly used, only a few studies have been carried out to investigate the humidifier performance. Rajalakshmi et al. [71] designed a gas bubbling humidifier using a humidification bottle with a removable sparger and a heater. The sparger could supply gas with tiny bubbles which create good gas-liquid contact and enhance the mass transfer between the liquid and gas. The amount of water vapor in the outlet gas can be measured. The outlet water vapor can be trapped through ice bath and silica gel. The amount of water picked-up by the outlet gas stream can be evaluated by measuring the weight difference of ice trap and silica gel before and after the experiment. It is concluded that for effective humidification, the 
key parameters for a sparger humidification system are the diameter and number of the holes, the diameter of the pipe, the flow rate, and the operating temperature. Hyun et al. [72] carried out an experiment to explore the relationship between the humidity and performance of a fuel cell. Their humidity measurement system is shown in Fig. 13. The inlet gas is humidified by a gas bubbling humidifier and the $\mathrm{RH}$ is measured by a hygrometer. The effects of the $\mathrm{RH}$ on the fuel cell performance at different operating conditions were obtained by them. However, the effects of the humidifier design parameters were not considered. Recently, Ahmaditaba et al. [73] conducted an experiment to investigate the effect of water temperature, water level and gas flow rate on the humidification performance. It is suggested that the increase of water temperature and water level in the container could enhance the gas humidification, while the increase of gas flow rate had an opposite effect. In order to achieve a simple control, Zhang [74] invented a two-stage bubbling humidifier which contains an intermediate heating stage. The humidity level is only dependent on the water temperature in this design. However, the dimension of this humidifier is enlarged due to the additional stage, which is not preferable for portable applications.

The gas bubbling humidifier is highly suitable for power plant because of the adequate humidification even in emergency shutdown operating conditions as reported in [72]. Nikiforow et al. [75] built a hybrid humidifier which contains a gas bubbling humidifier and a spray tower for a 50kW PEMFC pilot plant. They also built a gas bubbling humidifier model which indicates that the mass transfer rate between 
the gas and water does not limit the bubbler humidifier performance because of the sufficient residence time.

To improve the energy efficiency, the coolant water can be used to heat and to humidify the inlet gas. Vasu et al. [76] designed a gas bubbling humidification system which can continuously humidify the hydrogen over a wide range of flow rates. Their system can increase the stack efficiency by $6-19 \%$ according to their result owing to the coolant water recirculation. In the humidification system of the pilot plant reported by Nikiforow et al. [80], the gas bubbling humidifier is heated by the waste heat from the coolant water and the deionized water supplied to the humidifier is condensed from the outlet wet air, which results in high system efficiency.

Kuhn et al. [77] carried out an experiment based on gas bubbling humidifier to achieve exact and reproducible humidification levels in dynamic conditions. Dew point was measured, meanwhile the electrochemical impedance spectroscopy and direct neutron imaging were used to prove the reliability. The dew point temperature accuracy of their system can be controlled within 1-3 K and the fuel cell performance is highly reproducible.

In summary, this method provides good humidity control. The outlet gas can be humidified to the target $\mathrm{RH}$ by changing the water temperature and flow rate. Also, the coolant water can be used to heat and to humidify the inlet gas which improves the 
system efficiency significantly. It is highly suitable for power plant because of these advantages. The main drawback is that the liquid water in the form of droplets may be carried into the PEMFC which blocks the gas transfer path, thus proper measures need to be adopted to reduce this phenomenon [76]. In addition, the considerable pressure drop in the gas stream going through the gas bubbling humidifier may lead to significant parasitic losses [78].

\subsection{Direct water injection method}

In this method, water in the form of liquid or vapor is directly injected into the fuel cell inlet; since steam injection requires heating for steam generation, liquid water is used more often (as shown in Fig. 14). When water is transported from the anode to the cathode side due to electro-osmotic drag, the injected liquid water will evaporate to supply more water vapor. This method is very simple and the evaporation process of the liquid inside the fuel cell helps to absorb the waste heat which is beneficial for the heat management [79].

At the early stage, liquid water injection was seen as an effective method for humidification. However, the excessive amount of liquid water may cause electrode flooding that heavily influences the fuel cell performance and hence the liquid water injection method is dropped for this reason [80]. It is indicated that the flooding problem can be mitigated by using interdigitated flow field due to the shearing force of the gas flow which removes the liquid water in the inner layer of the electrode [80]. 
However, that method is only suitable for relatively small size applications at low flow rates. More effective methods are still needed for high flow rates and large scale applications.

To avoid the problem of water flooding, a mist eliminator is adopted to absorb the liquid water in the gas flow as shown in Fig. 15. This new design is also called “nozzle spray humidifier” [81]. Nozzle spray humidifier mainly consists of spray chamber, spray nozzle, and mist eliminator. The nozzle spray humidifier directly sprays liquid water into gas that flows through the humidifier. The mist eliminator is fixed at the top of a chamber in order to prevent the liquid water from blowing out with the reactant gas which may cause imprecise control of the RH. The gas that flows out from the mist eliminator is well humidified and then flows into the fuel cell inlet. The water that sprays out from the nozzle needs to be heated to a pre-set temperature and the $\mathrm{RH}$ of the outlet gas can be controlled by the temperature of the liquid water.

Different from the above injection humidification methods, Jung et al. [81] developed a water injection humidifier which uses a water retrieving unit to collect the liquid water from the gas. Zhang et al. [82] mitigated the flooding problem by the precise control of the injected water amount according to the gas flow rate. Sung et al. [83] adopted an ultrasonic atomizer which produces micro water droplets that can evaporate quickly. 
Despite the possibility of flooding, the excessive liquid water that flows into the fuel cell has an evaporative cooling effect which was not fully addressed in the previous study. In recent years, the method of direct water injection becomes attractive again for the advantage on heat management. The waste heat from the electrochemical reaction can heat the fuel cell stack to a high temperature which may cause the problem of membrane degradation and performance reduction [84]. Using direct water injection method is helpful for the heat rejection because of the evaporative cooling effect. Hwang et al. [85] investigated the humidification and cooling effect experimentally by adopting an atomizer and an air-providing tube at the inlet of fuel cell cathode (as shown in Fig. 16). This air-assist atomizer provides very fine droplets to improve the heat and mass transfer rates.

This atomizer performs well on humidifying the inlet air and cooling the system especially for high current densities where large amount of reactant gas and heat are involved. As Fig. 17 shows, the evaporative heat rejection rate is enhanced when the water injection rate increases from $1 \mathrm{ml} / \mathrm{min}$ to $5 \mathrm{ml} / \mathrm{min}$. This is mainly because that larger amount of liquid water leads to higher evaporation rate. In addition, higher operating temperature causes larger amount of water evaporation which results in higher evaporative heat rejection rate as shown in Fig. 17 (b). Also investigated is the effect of various operating parameters like injection water temperature, operating pressure and cathode $\mathrm{RH}$ in order to determine the optimal operating conditions [86]. 
Similar to the gas bubbling humidifier, liquid water injection method is also quite suitable for fuel cell stacks or high power applications because of the sufficient humidification capacity. Zhang et al. [82] designed a novel liquid water spray humidifier used for a $5 \mathrm{~kW}$ PEMFC. The waste heat of the PEMFC coolant was used to pre-heat the inlet gas, as shown in Fig. 18. No additional heater is needed and thus the overall efficiency is improved. In addition, it is easy to control by just adjusting the spray pressure. In the design of Nikiforow et al. [75], a liquid water spray tower is used to humidify the inlet gas for normal operating conditions of a $50 \mathrm{~kW}$ stationary PEMFC system. Further, the liquid water spray tower is also adopted for the $70 \mathrm{~kW}$ stationary PEMFC system built by NedStack Fuel Cell Technology [3].

In summary, the direct water injection method can provide effective and precise humidity control. The excessive water may cause flooding problem, however, it may also be beneficial for the AEMFC which will be described in Section 4 later. Moreover, the evaporative cooling effect of the liquid water provides additional cooling capacity and helps to mitigate the heat rejection requirement though it is not sufficient to replace the entire cooling system. The main drawback of this method is that it consumes energy due to pumping loss and heating of the injected water or steam. Using coolant water to pre-heat the inlet gas can improve the total efficiency in high power systems. In addition, the weight and complexity of the equipment are increased which makes this method unfavorable for portable or compact applications 


\subsection{Enthalpy wheel humidifier method}

The enthalpy wheel humidifier method is frequently adopted in heating ventilation and air conditioning industries [88]. It is also applicable for fuel cell humidification because of its advantages such as low pressure drop, lightweight and low cost [89]. As shown in Fig. 19, it uses a hygroscopic core with porous honeycomb-shaped columns [90] that can absorb the hot moisture from the fuel cell exhaust gas and delivery them to the dry inlet gas through rotation. The dry gas is humidified and heated by the humidifier and then flows into the fuel cell.

The diameter and thickness of the enthalpy wheel are key factors that affect the humidification level. Larger diameter and thickness lead to higher humidification levels. In practice, the size needs to be determined according to the power of the fuel cell. The humidification level can be controlled by adjusting the motor rotation speed or changing the gas flow rate [91].

Enthalpy wheel humidifiers have advantages in terms of cost, durability and reliability as reported in [88]. However, just a few studies have investigated its performance so far. Lao et al. [90] compared the performance of the membrane humidifier (which will be presented in Section 3.4) and enthalpy wheel humidifier. They reported that the enthalpy wheel humidifier performs better than membrane humidifier at high gas flow 
rates but worse at low gas flow rates, as shown in Fig. 20. In addition, it was predicted that the dynamic response capability of the enthalpy wheel humidifier is better than that of membrane humidifier. Their study supports the view that the enthalpy humidifier is more suitable for high power applications [77].

The main concern about the enthalpy wheel humidifier is that it may cause gas leakage and cross flow through the rotation. The gas leakage mainly consists of two components. One is the gas leaking between the interface of seal and core, the other one is the gas carried over by the rotating core [89]. To reduce the gas leakage, Casalegno et al. [88] tried to decrease the pressure difference between the two gas streams by adopting an innovative configuration as shown in Fig. 21. The conventional configuration (Fig. 21 (a)) generally places the humidifier after the air compressor and heat exchanger. This configuration leads to high pressure difference between the two gas streams due to the pressure drop through the humidifier and fuel cell. By adopting the new configuration as shown in Fig. 21 (b), the two gas streams can work at the same pressure. Thus the pressure difference between the two gas streams can be kept as low as possible and the possibility of gas leakage is reduced.

It can be concluded that this kind of humidifier can also be employed by stationary fuel cell systems or automobiles [77] due to the low cost and small pressure drop involved. In addition, the high durability increases its potential for PEMFC applications [88]. However, the gas leakage problem is still an issue that needs further 
investigation.

\subsection{Membrane humidifier method}

Wet gas or liquid water is used to humidify the dry gas in membrane humidifier method. Wet gas or liquid water flows through one side and dry gas flows through the other side of the membrane humidifier. It adopts a membrane (normally Nafion [92]) to separate the wet side and the dry side. Moist and heat can be transferred across the membrane to the dry side, while hydrogen or air is not allowed to transfer through the membrane neglecting the unavoidable small amount of crossover.

According to the different moist providers, membrane humidifier can be classified as gas-to-gas type and liquid-to-gas type. According to different shapes, the humidifier can be classified as planar (or plate-and-frame) type and tubular (or shell-and-tube) type. The former is normally used for gas-to-gas humidifier and the latter is normally used for liquid-to-gas humidifier. In the following subsections, the principle to evaluate the membrane humidifier performance will be described first. Then the gas-to-gas type and liquid-to-gas type will be described in detail separately.

\subsubsection{Evaluation principle}

Four performance metrics are commonly used in the literature to evaluate the performance of the membrane humidifier. 
1. Dry side outlet RH $\left(R H_{D O}\right)$. It is the direct indicator to evaluate the humidifier performance which can be calculated as:

$$
R H_{D O}=\frac{P}{P_{\text {sat }}}
$$

where $P$ is the water vapor partial pressure at the humidifier outlet, $P_{\text {sat }}$ is the saturated vapor pressure. In some cases, the dry side water concentration is also used to evaluate the humidifier performance. It is proportional to the $\mathrm{RH}$ at a constant temperature and can be converted to each other.

2. Dry side outlet dew point. The dew point is the temperature at which the gas is saturated with water vapor. The water vapor will condense to liquid water when the temperature is further cooled blow the dew point. The dew point is an indicator that reflects the water amount in the gas.

3. Water transfer rate (WTR). WTR is the rate of water transfer through the membrane from wet side to dry side. It can be calculated as the difference of the inlet and outlet water flow rate [93]:

$W T R=\frac{n \xi_{H_{2} O, D O}-n \xi_{H_{2} O, D I}}{A}$

where $n k_{\mathrm{H}_{2} \mathrm{O}, \mathrm{DO}}$ and $n k_{\mathrm{H}_{2} \mathrm{O}, \mathrm{DI}}$ are the water mass flow rate at the dry side outlet and inlet, respectively; $A$ is the membrane area. 
4. Water recovery ratio (WRR). WRR is the ratio of water amount transferred from wet side to the dry side and the water amount flow into the wet side inlet [94]. It can be calculated as [91]:

$W R R=\frac{n \xi_{\mathrm{H}_{2} \mathrm{O}, D \mathrm{O}}-n k_{\mathrm{H}_{2} \mathrm{O}, \mathrm{DI}}}{n k_{\mathrm{H}_{2} \mathrm{O}, W I}}$

where $n \&_{\mathrm{H}_{2} \mathrm{O}, \mathrm{WI}}$ is the water mass flow rate at the wet side inlet. WRR is not always proportional with the dry side outlet humidity. It becomes an important parameter if the wet side inlet humidity (or water content) is limited for the humidifier application. In some studies, WRR is also called "humidifier efficiency" [95].

Based on these metrics, the performance of different types of membrane humidifiers can be evaluated quantitatively. In some cases, a single performance metric is not enough to evaluate the performance of the humidifier [94]. Therefore, it is necessary to analyze the problem considering the specific operating condition when designing a humidifier. For example, McCarthy et al. [96] uses both dry side outlet RH and WTR as the evaluation criteria with response surface methodology.

\subsubsection{Gas-to-gas}

The gas-to-gas membrane humidifier uses the wet exhaust gas from the fuel cell outlet as the moist provider and normally it has two flow fields separated by the membrane, as shown in Fig. 22. The gas flow direction arrangement, performance and 
improvement method will be given in the following subsections.

\subsubsection{Flow direction arrangement}

There are three types of flow direction arrangements: parallel flow, counter flow and cross flow. The flow directions of the wet side and dry side are parallel in the parallel flow arrangement; opposite in the counter flow arrangement; and orthogonal in the cross flow arrangement.

Different flow direction arrangements may influence the humidification level. This is commonly encountered in the design of air ventilation systems [98,99], but it should also be considered in the membrane humidifier design. Houreh et al. [100] built a three dimensional CFD model of membrane humidifier. Performance of parallel flow and counter flow configurations are compared in their model. In this model, the cathode outlet gas is assumed to be saturated (RH 100\%) with temperature of $80{ }^{\circ} \mathrm{C}$. The dry side is moist free (RH $0 \%$ ) at $30^{\circ} \mathrm{C}$. The simulation results are shown in Figs. 23 and 24. The average water concentration in the dry side of the counter flow is 8.47 mol $\mathrm{m}^{-3}$ which is larger than the parallel flow which has an average water concentration of $6.58 \mathrm{~mol} \mathrm{~m}^{-3}$. Thus it shows that the performance of counter flow is better for water transfer. The operating condition used in their simulation is typical for the real operating condition of fuel cell. Thus the results are instructive for the design of humidifier to achieve better humidification performance. Park et al. [101] built a model based on the shell-and-tube configuration. Similar results are obtained 
according to their study. The counter flow is much effective than the parallel flow in heat and mass transfer. Actually, many other studies adopted the counter flow arrangement for their membrane humidifier [93,95,102].

For the cross flow configuration, Sabharwal et al. [94] conducted a sensitivity analysis about the cross flow membrane humidifier (as shown in Fig. 25) based on a two dimensional model. It is shown that the RH at the dry side outlet increases with the wet side flow rate, dry side and wet side pressure, wet side inlet $\mathrm{RH}$ and the number of plates. In addition, Kadylak et al. [103] proposed an effective mass transfer coefficient based on the previous work by Zhang and Niu [104,105]. Then they applied the latent effectiveness method, which is commonly used in the energy recovery ventilator systems, to the PEMFC membrane humidifier. This method can help to achieve the required composition at the outlets through setting the geometrical and flow parameters. However, neither of them compared the performance of different flow arrangements. Ahluwalia et al. [106] compared the performance of counter flow arrangement and cross flow arrangement using their novel composite membrane. The cross flow humidifier shows better performance in regard to water flux. Zhang et al. [98] compared the performance of the three flow arrangement based on an air ventilation system. The counter flow performs best according to their investigation and the parallel flow performs worst which shows agreement with the mentioned studies [100,106]. 
In regard to the humidifier configuration types, in most cases, the planar type is used in the gas-to-gas membrane humidifier. However, in the work of Park et al. [101] and Kang et al. [107], a tubular type is considered in the gas-to-gas humidifier. The tubular type humidifier adopts many compact tubes and can transfer the heat and mass effectively. However, mass production is difficult to achieve with low cost. In contrast, the planar type humidifier is cost efficient and mass producible [102]. Thus the planar type is more favorable.

\subsubsection{Performance}

The investigations on the gas-to-gas membrane humidifier are conducted by experimental and modeling methods.

In the experimental aspects, Cave et al. [93] built an experimental setup to investigate the effect of the flow rate on the humidifier performance. In their experiment, ten dew point sensors were fixed along the humidifier channel to measure the dew point temperature at specific locations as shown in Fig. 26. The flow rates of the dry side and wet side vary individually. It shows that the outlet dew point temperature increases with a decrease in the dry side flow rate. However, the wet side flow rate shows little effect on the dry side dew point. The moisture flux values across the membrane at different locations were also reported in their study.

In the modeling aspects, Yu et al. [102] built a static model of the planar humidifier 
based on Matlab/Simulink environment. Different design parameters (like heat and mass transfer area, membrane thickness and diffusivity, etc.) and operating parameters (like air flow rate, inlet humidity and operating pressure, etc.) are discussed in their study. The channel length, membrane thickness and the wet side inlet humidity are critical parameters in the design and operation of the humidifier. It is worth stressing that the effects of membrane thickness and diffusivity mentioned in this article are rarely reported in other literatures. An analytical model was built by Bhatia et al. [95] which is applicable for both planar and tubular humidifiers. Their model takes the effect of mass transfer on heat transfer into account, which was rarely considered in the previous studies. The performance of the humidifier under the different design parameters and operating conditions was studied. Also, a system study containing the fuel cell stack and humidifier was performed, which shows that the increase of current density results in the improvement of WTR but the decrease in the $\mathrm{RH}$ of the humidifier outlet. The combined effects should be considered when designing a humidifier in specific conditions.

Most of the studies focus on the performance of the humidifier only and assume the wet side inlet condition is independent with the dry side inlet condition. In practice, the wet side and dry side conditions are coupled with each other [95]. Kang et al. [107] connected the humidifier together with an air blower model and a one dimensional PEMFC model. The dynamic behaviors of the humidifier and PEMFC under various operating conditions were studied through this lumped model. 
The parameters and their influence on the humidifier performance are listed in Table 3 according to the mentioned experimental and modeling studies.

\subsubsection{Improvement methods}

Beside the studies on the conventional membrane humidifiers, some studies have also tried to improve the humidification performance by using new flow fields or new membranes.

Most membrane humidifiers adopt the conventional flow distributor which is similar with the flow channel used in the PEM fuel cell. In the past several years, metal foam flow distributor is becoming attractive to replace the conventional flow channel for the advantage on mass transfer and cost. Afshari et al. [108] adopted metal foam made of nickel as the humidifier flow distributor. Three configurations were considered in their study: adopting metal foam only at dry side, only at wet side and at both sides. Fig. 27 shows the outlet dew point temperature and water molar concentration of both the conventional and metal foam flow distributor. The exact values are listed in Table 4. It is clear that the metal foam flow distributor performs better than the conventional humidifier. In addition, owing to the zero temperature difference between the dry side and wet side, the membrane can have a relatively even temperature distribution which helps to improve the durability. Moreover, the porous metal foam leads to more water transfer due to the longer residence time [100]. 
Excepting the modification on the flow field, the membrane can also be improved in consideration of performance and cost. Most of the studies adopt commercial membranes (such as Nafion) as the moist and heat transfer medium. However, Samimi et al. [109] made efforts to design an appropriate membrane specifically for the membrane humidifier with high performance and low cost. Effects of membrane composition and nanoparticles were explored. It is shown that membranes prepared with polysulfone (PSU) polymer need low polymer percentage to achieve high porosity and humidification performance. Adding $\mathrm{TiO}_{2}$ can increase the hydrophilicity which helps to improve the humidification level. Meanwhile, the influence of operating parameters like pressure and temperature were also investigated. Ahluwalia et al. [106] investigated a humidifier adopting a composite membrane made by one perfluorosulfonic acid (PFSA) layer sandwiched by two PTFE layers. This membrane humidifier has high water vapor transfer flux and also shows advantages on cost and durability.

\subsubsection{Liquid-to-gas}

The liquid-to-gas membrane humidifier normally adopts a tubular configuration as shown in Fig. 28. It contains a bundle of membrane tubes which separate the liquid water and reactant gas that needs to be humidified. Liquid water is heated and transferred through the membrane in vapor phase. Reactant gas absorbs moist and heat from the water flow. 
Efforts on experiment and modeling investigations are devoted in order to improve the humidifier performance at various operating conditions. In the experimental aspect, steady and dynamic tests were carried out by Chen et al. [110] to achieve better humidification control. They used water vapor transfer rate as the evaluation principle. Results show that increasing the inlet air and water temperature or decreasing the air flow rate can help to improve the humidifier performance. The influence of the wet side channel pressure can be neglected which is different with the gas-to-gas humidifier.

In the modeling aspect, various models were developed in the previous studies. Chen et al. [110] built a thermodynamic model based on the control volume method as shown in Fig. 29. A new vapor transfer coefficient is used in their model which is fitted from their experimental results. Solsona et al. [111] developed a dynamic model using the approach similar to Chen et al. [110]. However, they mainly focused on reducing the parasitic loss through avoiding pumping loss induced by the deionized water. Further, they achieved a better control of $\mathrm{RH}$ and temperature of the outlet gas using a closed loop control strategy.

In order to consider the effect of channel dimensions and gas flow rates, Park et al. [112] developed a one-dimensional model which is easy to be applied in practice. However, it is so simplified that many factors are ignored. Such as the heat and mass distribution along the flow channel. Thus it is hard to investigate the influence of 
different flow arrangements, like parallel flow and counter flow.

In order to solve this problem, Kang et al. [113] built a quasi-two dimensional model which not only considers the heat and mass transfer through the membrane in radial direction but also considers the transfer along the channel in the axial direction. This method is also called $1 \mathrm{D}+1 \mathrm{D}$ model which was first adopted in the modeling of PEMFC $[79,114]$. The humidifier is discretized in the cross-sectional direction with three control volumes, including the shell, then membrane and the tube. In addition, the humidifier is separated into ten sections along the axial direction, as shown in Fig. 30. Various geometric parameters and operating parameters are studied based on both parallel flow and counter flow. Counter flow configuration shows better performance than the parallel flow, which is a similar result with the gas-to-gas humidifier.

Park et al. [115] went one step further on the humidifier modeling. Their model incorporates the previous model [113] with a one-dimensional dynamic vapor diffusion model through the membrane in which the membrane is separated into several zones, as shown in Fig. 31. This model can help to understand the response of the humidifier in transient operating conditions, as they described.

Based on the proposed modeling and experimental methods, performance of the liquid-to-gas humidifier is investigated under different operating conditions. The influence of the different operating parameters is summarized in Table 5. It should be 
noticed that, because the water is in liquid phase and is supplied by additional water source, thus the "water recovery ratio" mentioned in 3.4.1 is not applicable to be the evaluation criterion here.

\subsubsection{Summary}

In summary, the membrane humidifier has no moving parts compared with the enthalpy wheel humidifier, thus it saves energy which is attractive for automotive applications $[101,116]$. In addition, it also has the advantage of being easy to scale-up to suit the requirements of applications with different power demand. However, the exact control on the humidification level is limited [77]. In addition, for liquid-to-gas membrane humidifier, the membrane may be blocked by the impurities from liquid water for long-term operation [83].

\subsection{Exhaust gas recirculation method}

In order to reduce the complexity and cost, the concept of exhaust gas recirculation is applied to PEMFCs [117-122]. It is similar to the concept of enthalpy wheel and membrane humidifier which recirculate the exhaust gas to humidify the inlet gas. The difference is that, in the enthalpy wheel and membrane humidifier, inlet gas only absorbs moist and heat from the exhaust gas, however, in the recirculation system, the exhaust gas is mixed directly with the inlet gas together reducing the complexity of the system. Kim et al. [117] adopted cathode recirculation method to humidify the inlet air as shown in Fig. 32. The fuel cell performance is only slightly less than the 
fuel cell with external membrane humidifier. However, the water vapor condensation problem needs to be resolved to avoid water flooding. Yang et al. [118] built a "ladder design” PEMFC stack which supplies reactant gases in series through three single fuel cells. Exhaust gas is circulated to humidify the inlet gas. The fuel cell can work stably but the performance needs to be improved further. Also, their "ladder design" is not compact which is undesirable for its application. Wan et al. [119] condensed the outlet gas and recycled the condensed water to humidify the inlet gas. Their analysis shows that the amount of recovered water is sufficient for the inlet air humidification. However, it is not shown how to add the recovered water into the inlet gas sufficiently. In other words, the cost, power and water loss in the humidification process are not considered. Besides, patents [120,121] proposed some new recirculation methods for humidification such as adding a pressure regulator to manage the flow and pressure [120] and adopting a multiple-pass oxidant gas flow field to use the exhaust gas effectively [121]. Recently, Jiang et al. [122] conducted an experiment which recirculates the exhaust gas on both anode and cathode side. Two goals are achieved through their dual recirculation design. On one hand, the membrane can be hydrated without external humidifier. This helps to reduce the system complexity and improve the fast-start-up capability especially in sub-zero environment. On the other hand, fuel cell durability is also improved. However, the recirculation pump needs to consume energy which decreases the overall system efficiency.

\subsection{Summary}


The external humidification methods are reviewed in this section. In comparison with internal humidification methods, external humidification has a better humidification performance. The gas bubbling humidifier method and direct water injection method can be used for stationary applications because they are easy to control and have good humidification performance. However, they are not suitable for automobile applications because of the large size involved. The liquid needs to be heated which decreases the system efficiency. In addition, they may limit the fast-start-up at low temperature environment because it needs to take long time to heat the water in the humidifier [122]. The enthalpy wheel humidifier and the membrane humidifier can help to simplify the system and improve the overall efficiency. They are suitable for the automobile applications. The exhaust gas recirculation method simplifies the system further, however, the pumping loss reduces the efficiency along with other issues, such as water condensation, that needs to be resolved.

\section{Humidification for alkaline anion exchange membrane fuel cells}

The water management problem for AEMFCs is similar to the PEMFCs. However, differences still remain leading to different water management strategies. Fig. 33 describes the principle of AEMFC operation. On the cathode side, water is consumed through two ways: electro-osmotic drag and electrochemical reaction. The back diffusion is not sufficient to humidify the cathode side membrane [123]. Thus the cathode needs significant amount of water to meet the consumption demand. 
Recently studies show that, adding liquid water to the cathode inlet helps to improve the fuel cell performance [124-126]. Fig. 34 shows the simulation results conducted by Jiao et al. [124]. It indicates that proper amount of liquid water can improve the fuel cell performance further comparing to the cases in which the inlet gas is only humidified with water vapor. Results of the analytical models built by Jiao et al. [125] and Huo et al. [126] agree well with the above conclusion.

According to the above study, the direct water injection method may be more favorable for AEMFC humidification. However, the amount of water injected in the cathode inlet gas flow still needs to be controlled precisely to avoid water flooding.

\section{Conclusions and directions for the future research}

Water management is a critical issue for polymer electrolyte membrane fuel cells. Normally, the membrane needs to be hydrated to maintain the conductivity and durability. However, too much water may flood the porous electrode structure and block the gas transfer path which is detrimental to the fuel cell performance. Therefore, it is necessary to achieve a water-balance state in the fuel cell. Internal and external methods are used for the humidification of the membrane.

Internal humidification includes physical methods and chemical methods. The physical methods modify the fuel cell physical structure or optimize the operating conditions to achieve self-humidification. They need no additional equipment and 
have no parasitic loss. Thus it is very attractive for compact applications like portable devices and automobiles. However, proper water management can only be achieved under restricted operating conditions. Also, these methods may also insufficient to meet the humidification demand for high power devices. The chemical methods normally change the composition of membrane or electrode such as adding water retention materials to the membrane electrode assembly to retain the produced water. There is no need to change the fuel cell structure and relatively good performance can be achieved, which makes it applicable for portable or low power applications. However, the durability and stability still need to be confirmed.

External humidification includes gas bubbling humidifier method, direct water injection method, enthalpy wheel humidifier method, membrane humidifier method and exhaust gas recirculation method. The gas bubbling humidifier method and direct water injection method are commonly used at present because of the advantages such as high humidification performance and easiness of control. They are relatively suitable for stationary applications. However, the additional devices increase the volume and weight of the system, which is not favorable for compact applications such as automobile. The enthalpy wheel humidifier method makes use of the exhaust gas and helps to improve the overall efficiency, while the gas leakage still remain a challenge and the rotation of the enthalpy wheel induces parasitic loss. Membrane humidifier method is quite attractive due to the simple structure, light weight and good performance which are preferable for automotive applications. However, it 
should be noticed that the humidification performance is highly dependent on operating parameters such as flow rate, temperature and pressure, which should be considered comprehensively for practical applications. The exhaust gas recirculation method simplifies the system but the pumping loss is a drawback.

The humidification of alkaline anion exchange membrane fuel cells is also touched upon in this article briefly. The alkaline anion exchange membrane fuel cells need more water supply in comparison with polymer electrolyte membrane fuel cells because of the large water consumption at the cathode. Thus the direct water injection method may be advantageous, while it still need to be investigated comprehensively.

All of the above humidification methods have their own advantages and disadvantages. Proper humidification methods should be chosen according to the specific situations in consideration of complexity, weight, volume, and performance, etc. Then the influence of the operating conditions should also be considered to achieve an efficient control. For automobile applications, the smart humidification method is self-humidification with no additional devices because of the limited space. However, further investigation is still needed to achieve stable self-humidification under practical operating conditions.

\section{Acknowledgements}

This work was supported by the National Natural Science Foundation of China (Grant 
No. 51706153), the Natural Science Foundation of Tianjin, China (Grant No. 17JCZDJC31000), and the Natural Sciences and Engineering Research Council of Canada via a Discovery Grant.

\section{References}

[1] Daud WRW, Rosli RE, Majlan EH, Hamid SAA, Mohamed R, Husaini T. PEM fuel cell system control: A review. Renew Energy 2017;113:620-38. doi:10.1016/j.renene.2017.06.027.

[2] Jiao K, Li X. Water transport in polymer electrolyte membrane fuel cells. Prog Energy Combust Sci 2011;37:221-91. doi:10.1016/j.pecs.2010.06.002.

[3] Verhage AJL, Coolegem JF, Mulder MJJ, Yildirim MH, De Bruijn FA. 30,000 h operation of a $70 \mathrm{~kW}$ stationary PEM fuel cell system using hydrogen from a chlorine factory. Int J Hydrogen Energy 2013;38:4714-24. doi:10.1016/j.ijhydene.2013.01.152.

[4] Wang Y, Chen KS, Mishler J, Cho SC, Adroher XC. A review of polymer electrolyte membrane fuel cells: Technology, applications, and needs on fundamental research. Appl Energy 2011;88:981-1007. doi:10.1016/j.apenergy.2010.09.030.

[5] Endoh E, Terazono S, Widjaja H, Takimoto Y. Degradation Study of MEA for PEMFCs under Low Humidity Conditions. Electrochem Solid-State Lett 2004;7:A209. doi:10.1149/1.1739314.

[6] Sanchez DG, Ruiu T, Biswas I, Schulze M, Helmly S, Friedrich KA. Local 
impact of humidification on degradation in polymer electrolyte fuel cells. J Power Sources 2017;352:42-55. doi:10.1016/j.jpowsour.2017.03.057.

[7] Blanco M, Wilkinson DP. Investigation of the effect of microporous layers on water management in a proton exchange membrane fuel cell using novel diagnostic methods. Int J Hydrogen Energy 2014;39:16390-404. doi:10.1016/j.ijhydene.2014.07.147.

[8] Park J, Oh H, Lee Y Il, Min K, Lee E, Jyoung JY. Effect of the pore size variation in the substrate of the gas diffusion layer on water management and fuel cell performance. Appl Energy 2016;171:200-12. doi:10.1016/j.apenergy.2016.02.132.

[9] Ashra M, Shams M. The effects of flow-field orientation on water management in PEM fuel cells with serpentine channels. Appl Energy, In press. doi:10.1016/j.apenergy.2017.09.044.

[10] Dekel DR. Review of cell performance in anion exchange membrane fuel cells. J Power Sources 2018;375:158-69. doi:10.1016/j.jpowsour.2017.07.117.

[11] Qi Z, Kaufman A. PEM fuel cell stacks operated under dry-reactant conditions. J Power Sources 2002;109:469-76. doi:10.1016/S0378-7753(02)00111-8.

[12] Martins Belchor P, Camargo Forte MM, Ortiz Suman Carpenter DE. Parallel serpentine-baffle flow field design for water management in a proton exchange membrane fuel cell. Int J Hydrogen Energy 2012;37:11904-11. doi:10.1016/j.ijhydene.2012.05.091.

[13] Ge S, Li X, Hsing IM. Internally humidified polymer electrolyte fuel cells 
using water absorbing sponge. Electrochim Acta 2005;50:1909-16. doi:10.1016/j.electacta.2004.08.044.

[14] Santis M, Schmid D, Ruge M, Freunberger S, Büchi FN. Modular stack-internal air humidification concept-verification in a kW stack. Fuel Cells 2004;4:214-8. doi:10.1002/fuce.200400028.

[15] Wang ED, Shi PF, Du CY. A novel self-humidifying membrane electrode assembly with water transfer region for proton exchange membrane fuel cells. J Power Sources 2008;175:183-8. doi:10.1016/j.jpowsour.2007.09.075.

[16] Riascos LAM. Relative humidity control in polymer electrolyte membrane fuel cells without extra humidification. J Power Sources 2008;184:204-11. doi:10.1016/j.jpowsour.2008.06.032.

[17] Huizing R, Fowler M, Mérida W, Dean J. Design methodology for membrane-based plate-and-frame fuel cell humidifiers. J Power Sources 2008;180:265-75. doi:10.1016/j.jpowsour.2008.01.046.

[18] Chan SH, Goh SK, Jiang SP. A mathematical model of polymer electrolyte fuel cell with anode CO kinetics. Electrochim Acta 2003;48:1905-19. doi:10.1016/S0013-4686(03)00269-X.

[19] Noponen M, Mennola T, Mikkola M, Hottinen T, Lund P. Measurement of current distribution in a free-breathing PEMFC. J Power Sources 2002;106:304-12. doi:10.1016/S0378-7753(01)01063-1.

[20] Martin S, Garcia-Ybarra PL, Castillo JL. Long-term operation of a proton exchange membrane fuel cell without external humidification. Appl Energy 
2017;205:1012-20. doi:10.1016/j.apenergy.2017.08.157.

[21] Williams M V., Kunz HR, Fenton JM. Operation of Nafion-based PEM fuel cells with no external humidification: Influence of operating conditions and gas diffusion layers. J Power Sources 2004;135:122-34. doi:10.1016/j.jpowsour.2004.04.010.

[22] Cable News Network. Toyota's Futuristic, Freaky Fuel-Cell Car, http://money.cnn.com/2014/12/18/autos/toyota-mirai/.

[23] Konno N, Mizuno S, Nakaji H, Ishikawa Y. Development of Compact and High-Performance Fuel Cell Stack. SAE Int J Altern Powertrains 2015;4:1. doi:10.4271/2015-01-1175.

[24] Toyota

global. http://www.toyota-global.com/innovation/environmental_technology/te chnology_file/fuel_cell_hybrid.html.

[25] Hasegawa T, Imanishi H, Nada M, Ikogi Y. Development of the Fuel Cell System in the Mirai FCV. SAE Tech Pap 2016;2016-01-1185. doi:10.4271/2016-01-1185.

[26] Watanabe M, Uchida H, Seki Y, Emori M. Self-humidifying polymer electrolyte membranes for fuel cells. J Electrochem Soc 1996;143:3847-52.

[27] Watanabe M, Uchida H, Emori M. Analyses of self-humidification and suppression of gas crossover in Pt-dispersed polymer electrolyte membranes for fuel cells. J Electrochem Soc 1998;145:1137-41.

[28] Watanabe M, Uchida H, Emori M. Polymer electrolyte membranes 
incorporated with nanometer-size particles of $\mathrm{Pt}$ and/or metal-oxides: Experimental analysis of the self-humidification and suppression of gas-crossover in fuel cells. J Phys Chem B 1998;102:3129-37. doi:10.1021/jp973477e.

[29] Kwak SH, Yang TH, Kim CS, Yoon KH. The effect of platinum loading in the self-humidifying polymer electrolyte membrane on water uptake. J Power Sources 2003;118:200-4. doi:10.1016/S0378-7753(03)00094-6.

[30] Yang T, Yoon Y, Kim C, Kwak S, Yoon K. A novel preparation method for a self-humidifying polymer electrolyte membrane. J Power Sources 2002;106:328-32. doi:10.1016/S0378-7753(01)01025-4.

[31] Liu F, Yi B, Xing D, Yu J, Hou Z, Fu Y. Development of novel self-humidifying composite membranes for fuel cells. J Power Sources 2003;124:81-9. doi:10.1016/S0378-7753(03)00616-5.

[32] Yang B, Fu YZ, Manthiram A. Operation of thin Nafion-based self-humidifying membranes in proton exchange membrane fuel cells with dry $\mathrm{H}_{2}$ and $\mathrm{O}_{2}$. $\mathrm{J}$ Power Sources 2005;139:170-5. doi:10.1016/j.jpowsour.2004.07.010.

[33] Wang C, Liu ZX, Mao ZQ, Xu JM, Ge KY. Preparation and evaluation of a novel self-humidifying Pt/PFSA composite membrane for PEM fuel cell. Chem Eng J 2005;112:87-91. doi:10.1016/j.cej.2005.07.002.

[34] Wang L, Xing DM, Liu YH, Cai YH, Shao ZG, Zhai YF, et al. Pt/SiO 2 catalyst as an addition to Nafion/PTFE self-humidifying composite membrane. J Power 
Sources 2006;161:61-7. doi:10.1016/j.jpowsour.2006.03.068.

[35] Vengatesan S, Kim HJ, Lee SY, Cho E, Ha HY, Oh IH, et al. Operation of a proton exchange membrane fuel cell under non-humidified conditions using a membrane-electrode assemblies with composite membrane and electrode. J Power Sources 2007;167:325-9. doi:10.1016/j.jpowsour.2007.02.047.

[36] Zhang Y, Zhang H, Zhai Y, Zhu X, Bi C. Investigation of self-humidifying membranes based on sulfonated poly(ether ether ketone) hybrid with sulfated zirconia supported Pt catalyst for fuel cell applications. J Power Sources 2007;168:323-9. doi:10.1016/j.jpowsour.2007.03.007.

[37] Son DH, Sharma RK, Shul YG, Kim H. Preparation of Pt/zeolite-Nafion composite membranes for self-humidifying polymer electrolyte fuel cells. J Power Sources 2007;165:733-8. doi:10.1016/j.jpowsour.2006.11.090.

[38] Wang L, Yi BL, Zhang HM, Xing DM. $\mathrm{Cs}_{2.5} \mathrm{H}_{0.5} \mathrm{PWO}_{40} / \mathrm{SiO}_{2}$ as addition self-humidifying composite membrane for proton exchange membrane fuel cells. Electrochim Acta 2007;52:5479-83. doi:10.1016/j.electacta.2007.03.007.

[39] Liu YH, Yi B, Shao ZG, Wang L, Xing D, Zhang H. Pt/CNTs-Nafion reinforced and self-humidifying composite membrane for PEMFC applications. J Power Sources 2007;163:807-13. doi:10.1016/j.jpowsour.2006.09.065.

[40] Bi C, Zhang H, Zhang Y, Zhu X, Ma Y, Dai H, et al. Fabrication and investigation of $\mathrm{SiO}_{2}$ supported sulfated zirconia/Nafion ${ }^{\circledR}$ self-humidifying membrane for proton exchange membrane fuel cell applications. J Power Sources 2008;184:197-203. doi:10.1016/j.jpowsour.2008.06.019. 
[41] Liu Y, Nguyen T, Kristian N, Yu Y, Wang X. Reinforced and self-humidifying composite membrane for fuel cell applications. J Memb Sci 2009;330:357-62. doi:10.1016/j.memsci.2009.01.011.

[42] Peighambardoust SJ, Rowshanzamir S, Hosseini MG, Yazdanpour M. Self-humidifying nanocomposite membranes based on sulfonated poly(ether ether ketone) and heteropolyacid supported Pt catalyst for fuel cells. Int J Hydrogen Energy 2011;36:10940-57. doi:10.1016/j.ijhydene.2011.06.044.

[43] Lakshminarayana G, Nogami M, Kityk I V. Novel hybrid proton exchange membrane electrolytes for medium temperature non-humidified fuel cells. J Alloys Compd 2011;509:2238-42. doi:10.1016/j.jallcom.2010.10.192.

[44] Lee SH, Choi SH, Gopalan SA, Lee KP, Anantha-Iyengar G. Preparation of new self-humidifying composite membrane by incorporating graphene and phosphotungstic acid into sulfonated poly(ether ether ketone) film. Int J Hydrogen Energy 2014;39:17162-77. doi:10.1016/j.ijhydene.2014.07.181.

[45] Lee DC, Yang HN, Park SH, Park KW, Kim WJ. Self-humidifying Pt-graphene/ $\mathrm{SiO}_{2}$ composite membrane for polymer electrolyte membrane fuel cell. J Memb Sci 2015;474:254-62. doi:10.1016/j.memsci.2014.10.001.

[46] Díaz M, Ortiz A, Pringle JM, Wang X, Vijayaraghavan R, MacFarlane DR, et al. Protic plastic crystal/PVDF composite membranes for Proton Exchange Membrane Fuel Cells under non-humidified conditions. Electrochim Acta 2017;247:970-6. doi:10.1016/j.electacta.2017.07.076.

[47] Cha D, Jeon SW, Yang W, Kim D, Kim Y. Comparative performance 
evaluation of self-humidifying PEMFCs with short-side-chain and long-side-chain membranes under various operating conditions. Energy 2018;150:320-8. doi:10.1016/j.energy.2018.02.133.

[48] Zheng L, Zeng Q, Liao S, Zeng J. Highly performed non-humidification membrane electrode assembly prepared with binary $\mathrm{RuO}_{2}-\mathrm{SiO}_{2}$ oxide supported Pt catalysts as anode. Int J Hydrogen Energy 2012;37:13103-9. doi:10.1016/j.ijhydene.2012.04.110.

[49] Su H, Xu L, Zhu H, Wu Y, Yang L, Liao S, et al. Self-humidification of a PEM fuel cell using a novel $\mathrm{Pt} / \mathrm{SiO}_{2} / \mathrm{C}$ anode catalyst. Int $\mathrm{J}$ Hydrogen Energy 2010;35:7874-80. doi:10.1016/j.ijhydene.2010.05.081.

[50] Park CH, Lee SY, Hwang DS, Shin DW, Cho DH, Lee KH, et al. Nanocrack-regulated self-humidifying membranes. Nature 2016;532:480-3. doi:10.1038/nature17634.

[51] Nature News \& Views. Materials science: Cracks help membranes to stay hydrated, https://www.nature.com/articles/532445a\#f1

[52] Vengatesan S, Kim HJ, Lee SY, Cho E, Yong Ha H, Oh IH, et al. High temperature operation of PEMFC: A novel approach using MEA with silica in catalyst layer. Int J Hydrogen Energy 2008;33:171-8. doi:10.1016/j.ijhydene.2007.09.021.

[53] Han M, Chan SH, Jiang SP. Investigation of self-humidifying anode in polymer electrolyte fuel cells. Int J Hydrogen Energy 2007;32:385-91. doi:10.1016/j.ijhydene.2006.08.034. 
[54] Poh CK, Tian Z, Bussayajarn N, Tang Z, Su F, Lim SH, et al. Performance enhancement of air-breathing proton exchange membrane fuel cell through utilization of an effective self-humidifying platinum-carbon catalyst. J Power Sources 2010;195:8044-51. doi:10.1016/j.jpowsour.2010.06.103.

[55] Lo AY, Huang CY, Sung LY, Louh RF. Electrophoretic Deposited Pt/C/SiO Anode for Self-Humidifying and Improved Catalytic Activity in PEMFC. Electrochim Acta 2015;180:610-5. doi:10.1016/j.electacta.2015.07.101.

[56] Choi I, Lee H, Lee KG, Ahn SH, Lee SJ, Kim HJ, et al. Characterization of self-humidifying ability of $\mathrm{SiO}_{2}$-supported Pt catalyst under low humidity in PEMFC. Appl Catal B Environ 2015;168-169:220-7. doi:10.1016/j.apcatb.2014.12.026.

[57] Hung TF, Liao SH, Li CY, Chen-Yang YW. Effect of sulfonated carbon nanofiber-supported Pt on performance of Nafion-based self-humidifying composite membrane for proton exchange membrane fuel cell. J Power Sources 2011;196:126-32. doi:10.1016/j.jpowsour.2010.07.017.

[58] Liang H, Zheng L, Liao S. Self-humidifying membrane electrode assembly prepared by adding PVA as hygroscopic agent in anode catalyst layer. Int J Hydrogen Energy 2012;37:12860-7. doi:10.1016/j.ijhydene.2012.05.083.

[59] Tsai C-H, Yang F-L, Chang C-H, Chen-Yang YW. Microwave-assisted synthesis of silica aerogel supported pt nanoparticles for self-humidifying proton exchange membrane fuel cell. Int J Hydrogen Energy 2012;37:7669-76. doi:10.1016/j.ijhydene.2012.01.104. 
[60] Hou S, Liao S, Dang D, Zou H, Shu T, Du L. Self-humidifying membrane electrode assembly prepared by adding microcrystalline cellulose in anode catalyst layer as preserve moisture. Int J Hydrogen Energy 2014;39:12842-8. doi:10.1016/j.ijhydene.2014.06.067.

[61] Ko YD, Yang HN, Züttel A, Kim SD, Kim WJ. Membrane electrode assembly fabricated with the combination of $\mathrm{Pt} / \mathrm{C}$ and hollow shell structured-Pt-SiO @ $\mathrm{ZrO}_{2}$ sphere for self-humidifying proton exchange membrane fuel cell. J Power Sources 2017;367:8-16. doi:10.1016/j.jpowsour.2017.09.043.

[62] Yang HN, Lee WH, Choi BS, Ko YD, Yi SC, Kim WJ. Self-humidifying Pt-C/Pt-TiO 2 dual-catalyst electrode membrane assembly for proton-exchange membrane fuel cells. Energy 2017;120:12-9. doi:10.1016/j.energy.2016.12.054.

[63] Koh B, Yoo J, Jang E, Rajendiran V. Electrochemistry Communications Fabrication of highly effective self-humidifying membrane electrode assembly for proton exchange membrane fuel cells via electrostatic spray deposition. Electrochem Commun 2018;93:76-80. doi:10.1016/j.elecom.2018.06.005.

[64] Park H. Effect of the hydrophilic and hydrophobic characteristics of the gas diffusion medium on polymer electrolyte fuel cell performance under non-humidification condition. Energy Convers Manag 2014;81:220-30. doi:10.1016/j.enconman.2014.02.029.

[65] Kong IM, Choi JW, Kim S Il, Lee ES, Kim MS. Experimental study on the self-humidification effect in proton exchange membrane fuel cells containing 
double gas diffusion backing layer. Appl Energy 2015;145:345-453. doi:10.1016/j.apenergy.2015.02.027.

[66] Kong IM, Jung A, Kim MS. Investigations on the double gas diffusion backing layer for performance improvement of self-humidified proton exchange membrane fuel cells. Appl Energy 2016;176:149-56. doi:10.1016/j.apenergy.2016.05.057.

[67] Breitwieser M, Moroni R, Schock J, Schulz M, Schillinger B, Pfeiffer F, et al. Water management in novel direct membrane deposition fuel cells under low humidification. Int J Hydrogen Energy 2016;41:11412-7. doi:10.1016/j.ijhydene.2016.05.018.

[68] Klingele M, Breitwieser M, Thiele S. Direct deposition of proton exchange membranes enabling high performance hydrogen fuel cells. J Mater Chem A Mater Energy Sustain 2015;3:11239-45. doi:10.1039/C5TA01341K.

[69] Peng S, Xu X, Lu S, Sui PC, Djilali N, Xiang Y. A self-humidifying acidic-alkaline bipolar membrane fuel cell. J Power Sources 2015;299:273-9. doi:10.1016/j.jpowsour.2015.08.104.

[70] Li Q, Gong J, Peng S, Lu S, Sui PC, Djilali N, et al. Theoretical design strategies of bipolar membrane fuel cell with enhanced self-humidification $\begin{array}{llll}\text { behavior. } & \text { J } & \text { Power }\end{array}$ doi:10.1016/j.jpowsour.2016.01.016.

[71] Rajalakshmi N, Sridhar P, Dhathathreyan KS. Identification and characterization of parameters for external humidification used in polymer 
electrolyte membrane fuel cells. J Power Sources 2002;109:452-7. doi:10.1016/S0378-7753(02)00102-7.

[72] Hyun D, Kim J. Study of external humidification method in proton exchange membrane fuel cell. J Power Sources 2004;126:98-103. doi:10.1016/j.jpowsour.2003.08.041.

[73] Ahmaditaba AH, Afshari E, Asghari S. An experimental study on the bubble humidification method of polymer electrolyte membrane fuel cells. Energy Sources, Part A Recover Util Environ Eff 2018;40:1508-19. doi:10.1080/15567036.2018.1477877.

[74] Zhang C. Gas humidifier. Patent No. US6715743B2; 2004.

[75] Nikiforow K, Ihonen J, Keränen T, Karimäki H, Alopaeus V. Modeling and experimental validation of $\mathrm{H}_{2}$ gas bubble humidifier for a $50 \mathrm{~kW}$ stationary PEMFC system. Int J Hydrogen Energy 2014;39:9768-81. doi:10.1016/j.ijhydene.2014.04.058.

[76] Vasu G, Tangirala AK, Viswanathan B, Dhathathreyan KS. Continuous bubble humidification and control of relative humidity of $\mathrm{H}_{2}$ for a PEMFC system. Int J Hydrogen Energy 2008;33:4640-8. doi:10.1016/j.ijhydene.2008.05.051.

[77] Kuhn R, Krüger P, Kleinau S, Dawson M, Geyer J, Roscher M, et al. Dynamic fuel cell gas humidification system. Int J Hydrogen Energy 2012;37:7702-9. doi:10.1016/j.ijhydene.2012.01.143.

[78] Sridhar P, Perumal R, Rajalakshmi N, Raja M, Dhathathreyan KS. Humidification studies on polymer electrolyte membrane fuel cell. J Power 
Sources 2001;101:72-8. doi:10.1016/S0378-7753(01)00625-5.

[79] Nguyen $\mathrm{T}$ V. A Water and Heat Management Model for Proton-Exchange-Membrane Fuel Cells. J Electrochem Soc 1993;140:2178-86. doi:10.1149/1.2220792.

[80] Wood DL, Yi YS, Nguyen T V. Effect of direct liquid water injection and interdigitated flow field on the performance of proton exchange membrane fuel cells. $\quad$ Electrochim $\quad$ Acta $\quad 1998 ; 43: 3795-809$. doi:10.1016/S0013-4686(98)00139-X.

[81] Jung SH, Kim SL, Kim MS, Park Y, Lim TW. Experimental study of gas humidification with injectors for automotive PEM fuel cell systems. J Power Sources 2007;170:324-33. doi:10.1016/j.jpowsour.2007.04.013.

[82] Zhang H, Qian Z, Yang D, Ma J. Design of an air humidifier for a $5 \mathrm{~kW}$ proton exchange membrane fuel cell stack operated at elevated temperatures. Int J Hydrogen Energy 2013;38:12353-62. doi:10.1016/j.ijhydene.2013.07.050.

[83] Sung CC, Bai CY, Chen JH, Chang SJ. Controllable fuel cell humidification by ultrasonic atomization. J Power Sources 2013;239:151-6. doi:10.1016/j.jpowsour.2013.03.076.

[84] Dadda B, Abboudi S, Zarrit R, Ghezal A. Heat and mass transfer influence on potential variation in a PEMFC membrane. Int $\mathrm{J}$ Hydrogen Energy 2014;39:15238-45. doi:10.1016/j.ijhydene.2014.04.217.

[85] Hwang SH, Kim MS. An experimental study on the cathode humidification and evaporative cooling of polymer electrolyte membrane fuel cells using direct 
water injection method at high current densities. Appl Therm Eng 2016;99:635-44. doi:10.1016/j.applthermaleng.2016.01.091.

[86] Choi EJ, Hwang SH, Park J, Kim MS. Parametric analysis of simultaneous humidification and cooling for PEMFCs using direct water injection method. Int J Hydrogen 2017;42:12531-42. doi:10.1016/j.ijhydene.2017.03.201.

[87] Iyuke SE, Mohamad AB, Daud WRW. Estimation of humidification load from humidifier column by convective heat transfer in water-air-vapour system. Chem Eng Sci 2001;56:4949-56. doi:10.1016/S0009-2509(01)00137-3.

[88] Casalegno A, De Antonellis S, Colombo L, Rinaldi F. Design of an innovative enthalpy wheel based humidification system for polymer electrolyte fuel cell. Int J Hydrogen Energy 2011;36:5000-9. doi:10.1016/j.ijhydene.2011.01.012.

[89] Humidicore ${ }^{\mathrm{TM}}$ Fuel Cell Humidification System. http://www.humidicore.com/.

[90] Lao X, Ma S, Zhao J, Zheng H, Zhuge W, Zhang Y, et al. Comparative study of membrane humidifier and enthalpy wheel humidifier for large power fuel cell system. J Fuel Cell Sci Technol 2009;6:014501-1-014501-3. doi:10.1115/1.2971175.

[91] Eisler EA, Gutenmann DA. Apparatus and method for dynamic control of an enthalpy wheel in a fuel cell system. Patent No. US7112378B2; 2006.

[92] Perma Pure.

http://www.permapure.com/products/gas-humidification/fc-series-humidifiers/.

[93] Cave P, Mérida W. Water flux in membrane fuel cell humidifiers: Flow rate 
and channel location effects. J Power Sources 2008;175:408-18. doi:10.1016/j.jpowsour.2007.08.103.

[94] Sabharwal M, Duelk C, Bhatia D. Two-dimensional modeling of a cross flow plate and frame membrane humidifier for fuel cell applications. J Memb Sci 2012;409-410:285-301. doi:10.1016/j.memsci.2012.03.066.

[95] Bhatia D, Sabharwal M, Duelk C. Analytical model of a membrane humidifier for polymer electrolyte membrane fuel cell systems. Int J Heat Mass Transf 2013;58:702-17. doi:10.1016/j.ijheatmasstransfer.2012.11.033.

[96] McCarthy E, Flick S, Mérida W. Response surface methods for membrane humidifier performance. J Power Sources 2013;239:399-408. doi:10.1016/j.jpowsour.2013.04.002.

[97] Min J, Su M. Performance analysis of a membrane-based enthalpy exchanger: Effects of the membrane properties on the exchanger performance. J Memb Sci 2010;348:376-82. doi:10.1016/j.memsci.2009.11.032.

[98] Zhang LZ, Liang CH, Pei LX. Conjugate heat and mass transfer in membrane-formed channels in all entry regions. Int $\mathrm{J}$ Heat Mass Transf 2010;53:815-24. doi:10.1016/j.ijheatmasstransfer.2009.11.043.

[99] Zhang LZ. Heat and mass transfer in a cross-flow membrane-based enthalpy exchanger under naturally formed boundary conditions. Int J Heat Mass Transf 2007;50:151-62. doi:10.1016/j.ijheatmasstransfer.2006.06.025.

[100] Baharlou Houreh N, Afshari E. Three-dimensional CFD modeling of a planar membrane humidifier for PEM fuel cell systems. Int J Hydrogen Energy 
2014;39:14969-79. doi:10.1016/j.ijhydene.2014.07.037.

[101] Park SK, Choe SY, Choi S ho. Dynamic modeling and analysis of a shell-and-tube type gas-to-gas membrane humidifier for PEM fuel cell applications. Int J Hydrogen Energy 2008;33:2273-82. doi:10.1016/j.ijhydene.2008.02.058.

[102] Yu S, Im S, Kim S, Hwang J, Lee Y, Kang S, et al. A parametric study of the performance of a planar membrane humidifier with a heat and mass exchanger model for design optimization. Int J Heat Mass Transf 2011;54:1344-51. doi:10.1016/j.ijheatmasstransfer.2010.11.054.

[103] Kadylak D, Cave P, Mérida W. Effectiveness correlations for heat and mass transfer in membrane humidifiers. Int J Heat Mass Transf 2009;52:1504-9. doi:10.1016/j.ijheatmasstransfer.2008.09.002.

[104] Zhang LZ, Niu JL. Effectiveness Correlations for Heat and Moisture Transfer Processes in an Enthalpy Exchanger With Membrane Cores. J Heat Transfer 2002;124:922-9. doi:10.1115/1.1469524.

[105] Niu JL, Zhang LZ. Membrane-based Enthalpy Exchanger: Material considerations and clarification of moisture resistance. J Memb Sci 2001;189:179-91. doi:10.1016/S0376-7388(00)00680-3.

[106] Ahluwalia RK, Wang X, Johnson WB, Berg F, Kadylak D. Performance of a cross-flow humidifier with a high flux water vapor transport membrane. J Power Sources 2015;291:225-38. doi:10.1016/j.jpowsour.2015.05.013.

[107] Kang S, Min K, Yu S. Dynamic modeling of a proton exchange membrane fuel 
cell system with a shell-and-tube gas-to-gas membrane humidifier. Int J Hydrogen Energy 2012;37:5866-75. doi:10.1016/j.ijhydene.2011.12.063.

[108] Afshari E, Baharlou Houreh N. Performance analysis of a membrane humidifier containing porous metal foam as flow distributor in a PEM fuel cell system. Energy Convers Manag 2014;88:612-21. doi:10.1016/j.enconman.2014.08.067.

[109] Samimi A, Mousavi SA, Moallemzadeh A, Roostaazad R, Hesampour M, Pihlajamäki A, et al. Preparation and characterization of PES and PSU membrane humidifiers. J Memb Sci 2011;383:197-205. doi:10.1016/j.memsci.2011.08.043.

[110] Chen D, Li W, Peng H. An experimental study and model validation of a membrane humidifier for PEM fuel cell humidification control. J Power Sources 2008;180:461-7. doi:10.1016/j.jpowsour.2008.02.055.

[111] Solsona M, Kunusch C, Ocampo-Martinez C. Control-oriented model of a membrane humidifier for fuel cell applications. Energy Convers Manag 2017;137:121-9. doi:10.1016/j.enconman.2017.01.036.

[112] Park S, Oh I. An analytical model of Nafion ${ }^{\mathrm{TM}}$ membrane humidifier for proton exchange membrane fuel cells. J Power Sources 2009;188:498-501. doi:10.1016/j.jpowsour.2008.12.018.

[113] Kang S, Min K, Yu S. Two dimensional dynamic modeling of a shell-and-tube water-to-gas membrane humidifier for proton exchange membrane fuel cell. Int J Hydrogen Energy 2010;35:1727-41. doi:10.1016/j.ijhydene.2009.11.105. 
[114] Freunberger SA, Santis M, Schneider IA, Wokaun A, Büchi FN. In-Plane Effects in Large-Scale PEMFCs. J Electrochem Soc 2006;153:A396-405. doi:10.1149/1.2150150.

[115] Park S, Jung D. Effect of operating parameters on dynamic response of water-to-gas membrane humidifier for proton exchange membrane fuel cell vehicle. Int J Hydrogen Energy 2013;38:7114-25. doi:10.1016/j.ijhydene.2013.03.170.

[116] Ramya K, Sreenivas J, Dhathathreyan KS. Study of a porous membrane humidification method in polymer electrolyte fuel cells. Int J Hydrogen Energy 2011;36:14866-72. doi:10.1016/j.ijhydene.2010.12.088.

[117] Kim BJ, Kim MS. Studies on the cathode humidification by exhaust gas recirculation for PEM fuel cell. Int J Hydrogen Energy 2012;37:4290-9. doi:10.1016/j.ijhydene.2011.11.103.

[118] Yang T, Shi P, Du C. Study on self-humidified PEMFC with reactant circulation. Electrochim Acta 2006;51:5618-25. doi:10.1016/j.electacta.2006.02.036.

[119] Wan ZM, Wan JH, Liu J, Tu ZK, Pan M, Liu ZC, et al. Water recovery and air humidification by condensing the moisture in the outlet gas of a proton exchange membrane fuel cell stack. Appl Therm Eng 2012;42:173-8. doi:10.1016/j.applthermaleng.2012.02.045.

[120] Breault RD. High temperature reactant recycling for PEM fuel cell humidification. Patent No. US7067209B2; 2006. 
[121] Hild T, Herbig T, Wnendt B. Cathod humidification of a PEM fuel cell through exhaust gas recirculation into a positive dispalcement compressor. Patent No. US7781084B2; 2010.

[122] Jiang H, Xu L, Fang C, Zhao X, Hu Z, Li J, et al. Experimental study on dual recirculation of polymer electrolyte membrane fuel cell. Int J Hydrogen Energy 2017;42:18551-9. doi:10.1016/j.ijhydene.2017.04.183.

[123] Gottesfeld S, Dekel DR, Page M, Bae C, Yan Y, Zelenay P, et al. Anion exchange membrane fuel cells: Current status and remaining challenges. J Power Sources 2017:1-15. doi:10.1016/j.jpowsour.2017.08.010.

[124] Jiao K, Huo S, Zu M, Jiao D, Chen J, Du Q. An analytical model for hydrogen alkaline anion exchange membrane fuel cell. Int J Hydrogen Energy 2015;40:3300-12. doi:10.1016/j.ijhydene.2014.12.091.

[125] Jiao K, He P, Du Q, Yin Y. Three-dimensional multiphase modeling of alkaline anion exchange membrane fuel cell. Int J Hydrogen Energy 2014;39:5981-95. doi:10.1016/j.ijhydene.2014.01.180.

[126] Huo S, Park JW, He P, Wang D, Jiao K. Analytical modeling of liquid saturation jump effect for hydrogen alkaline anion exchange membrane fuel cell. Int J Heat Mass Transf 2017;112:891-902. doi:10.1016/j.ijheatmasstransfer.2017.04.137. 


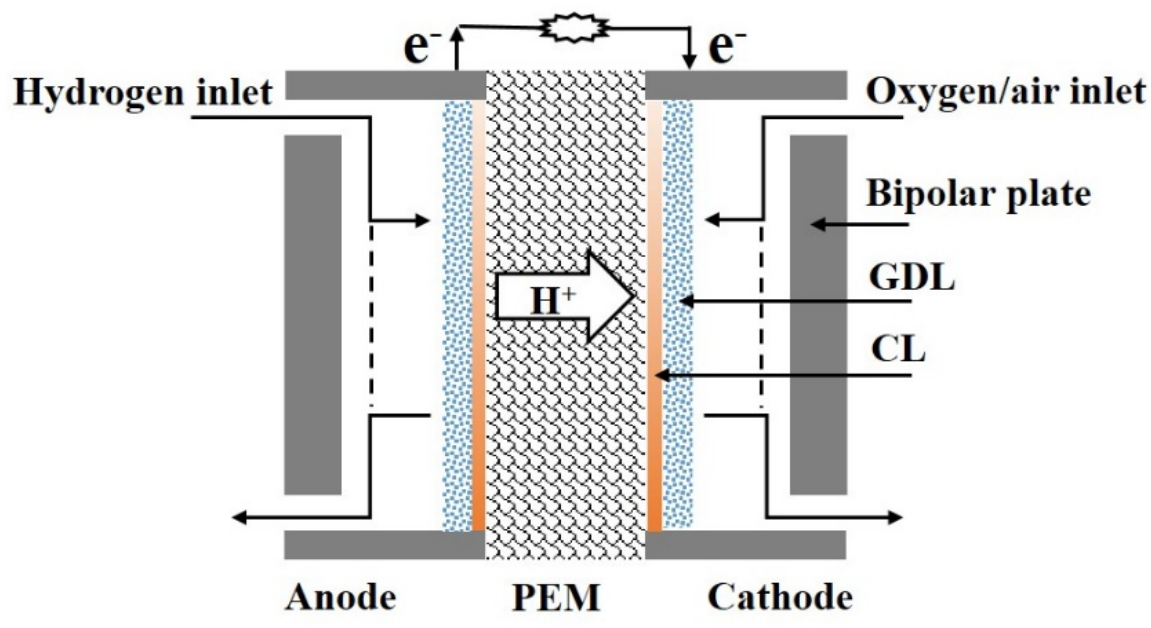

Fig. 1. Schematic of a proton exchange membrane fuel cell (PEMFC). 
(a)
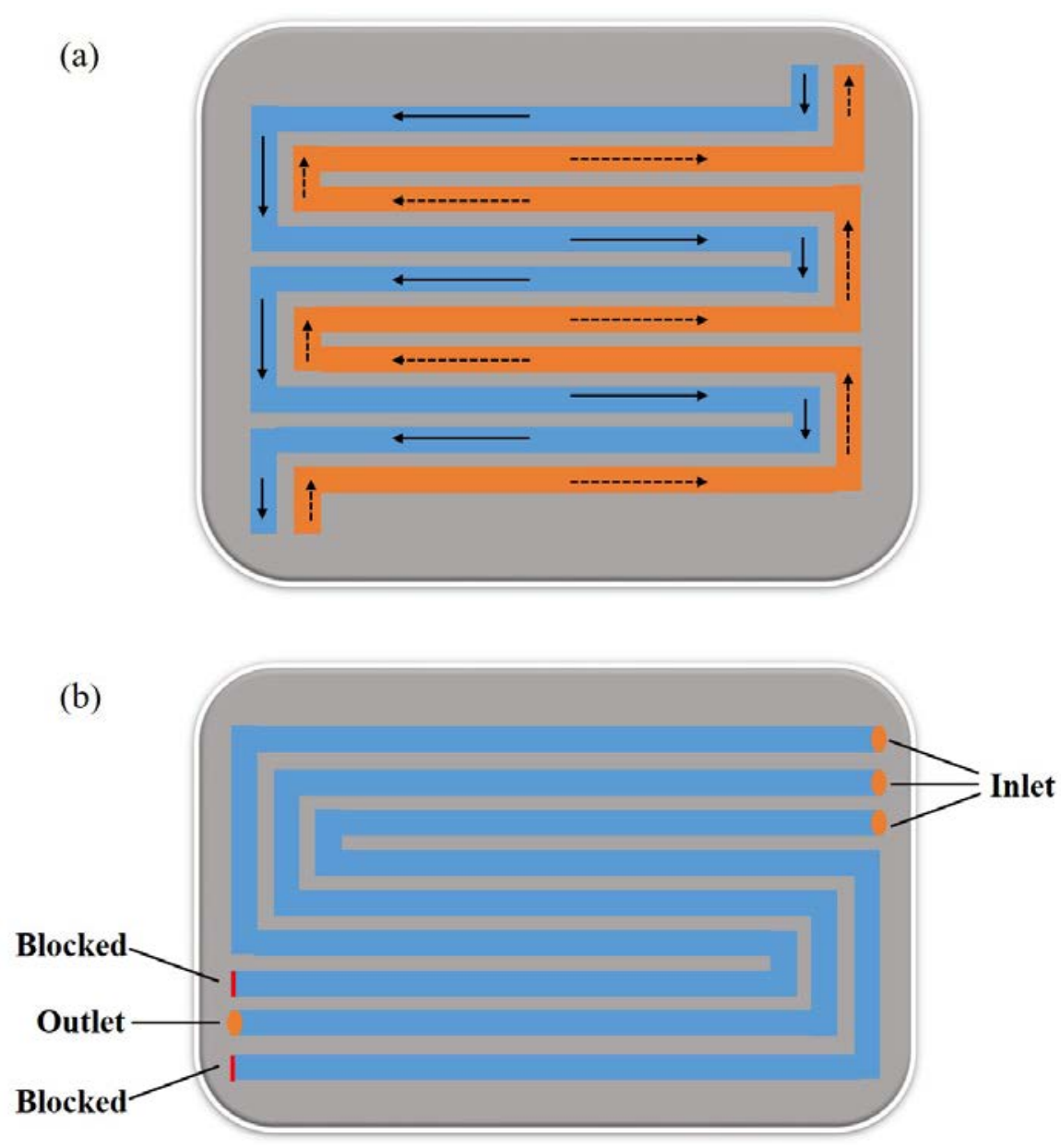

Fig. 2. (a) Flow field with two flow channels of different flow directions designed by Qi and Kaufman [11]; (b) Schematic of parallel serpentine-baffle flow field [12]. 


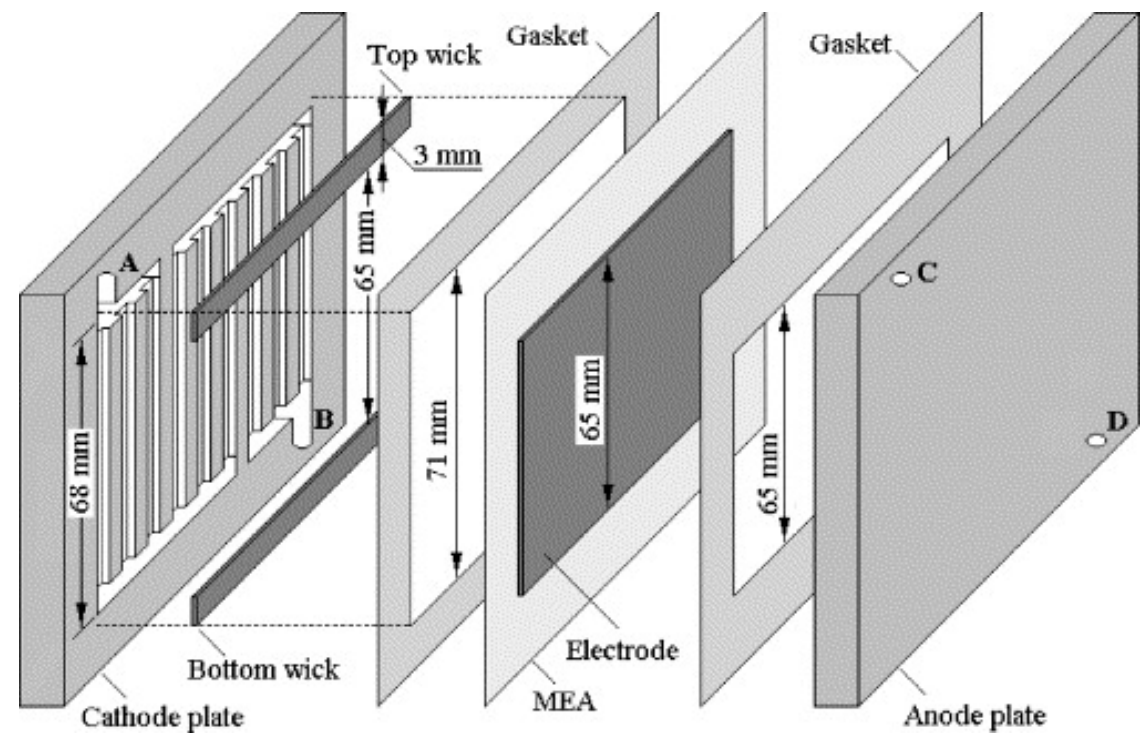

Fig. 3. Schematic of the fuel cell structure with two sponge wicks at the cathode [13]. 


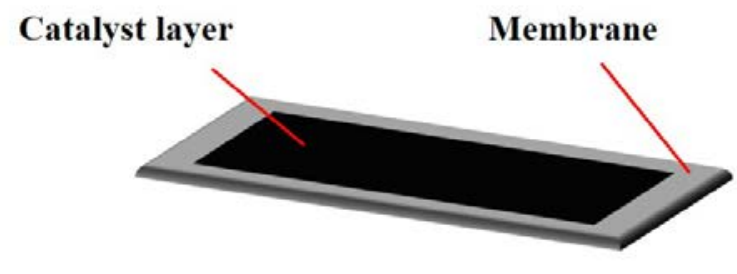

(a)

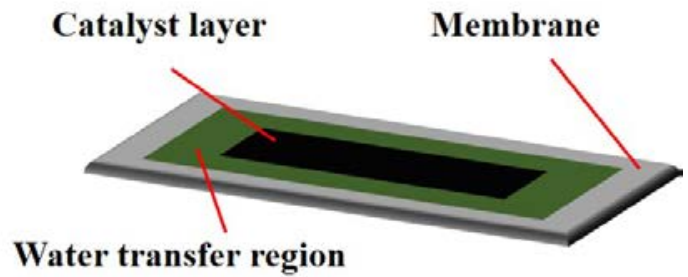

(b)

Fig. 4. Comparison of (a) the conventional membrane electrode assembly (MEA) and (b) the self-humidification MEA [15]. 


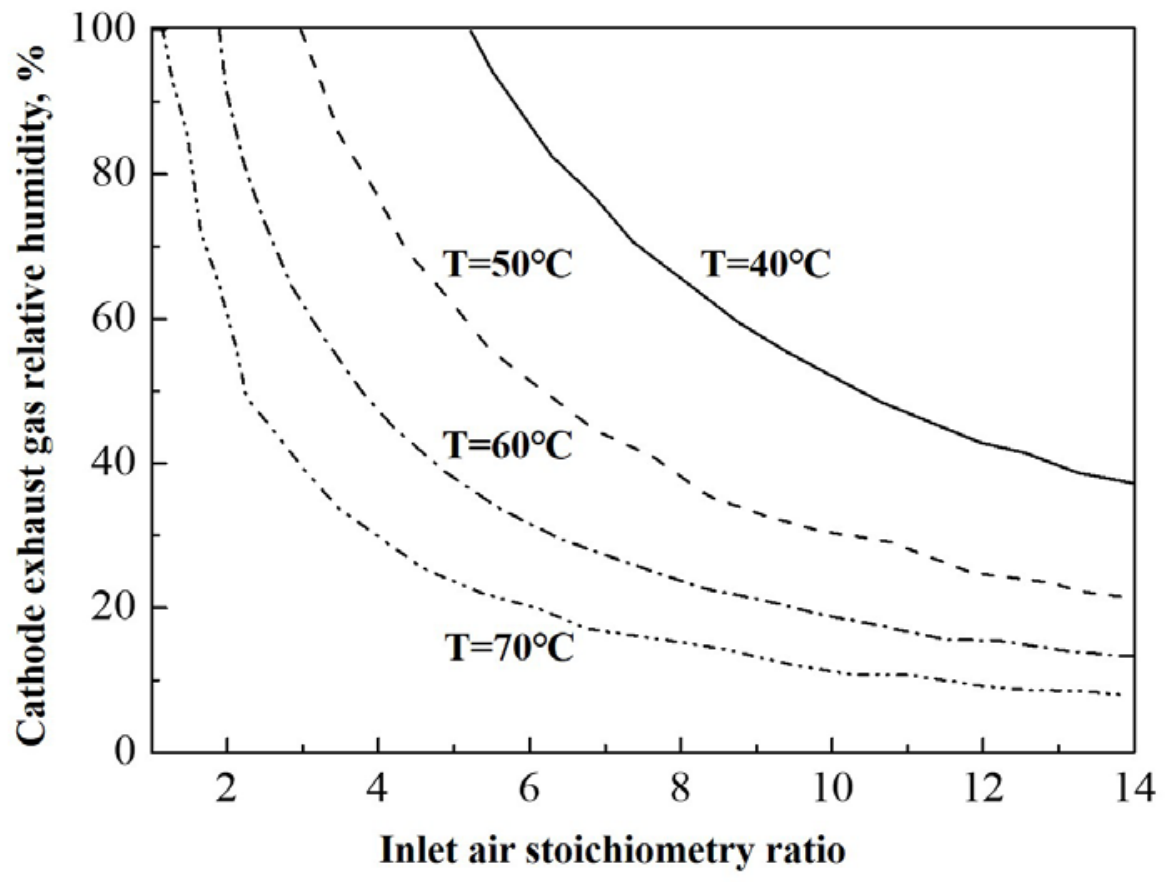

Fig. 5. Dependence of cathode exhaust gas relative humidity on the inlet air stoichiometry ratio with dry inlet reactant gases on both sides [20]. 
Thinner electrolyte membrane

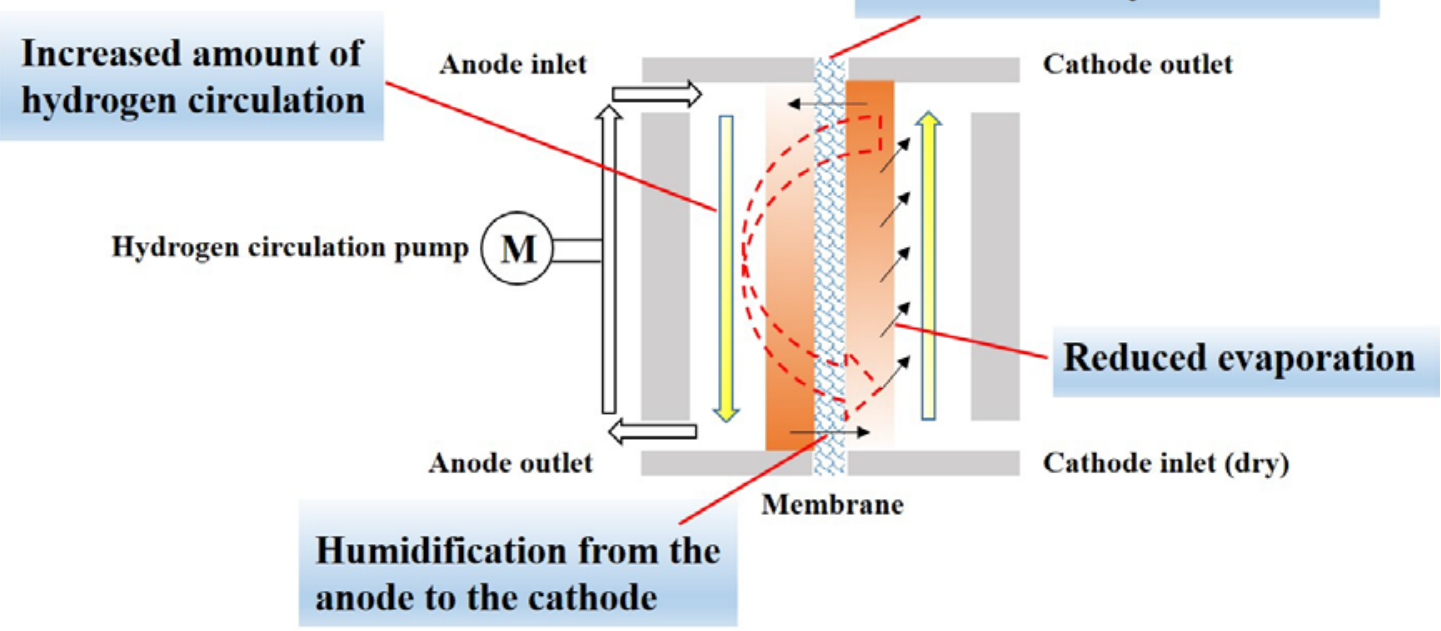

Fig. 6. Concept of self-humidification adopted by Toyota [25]. 


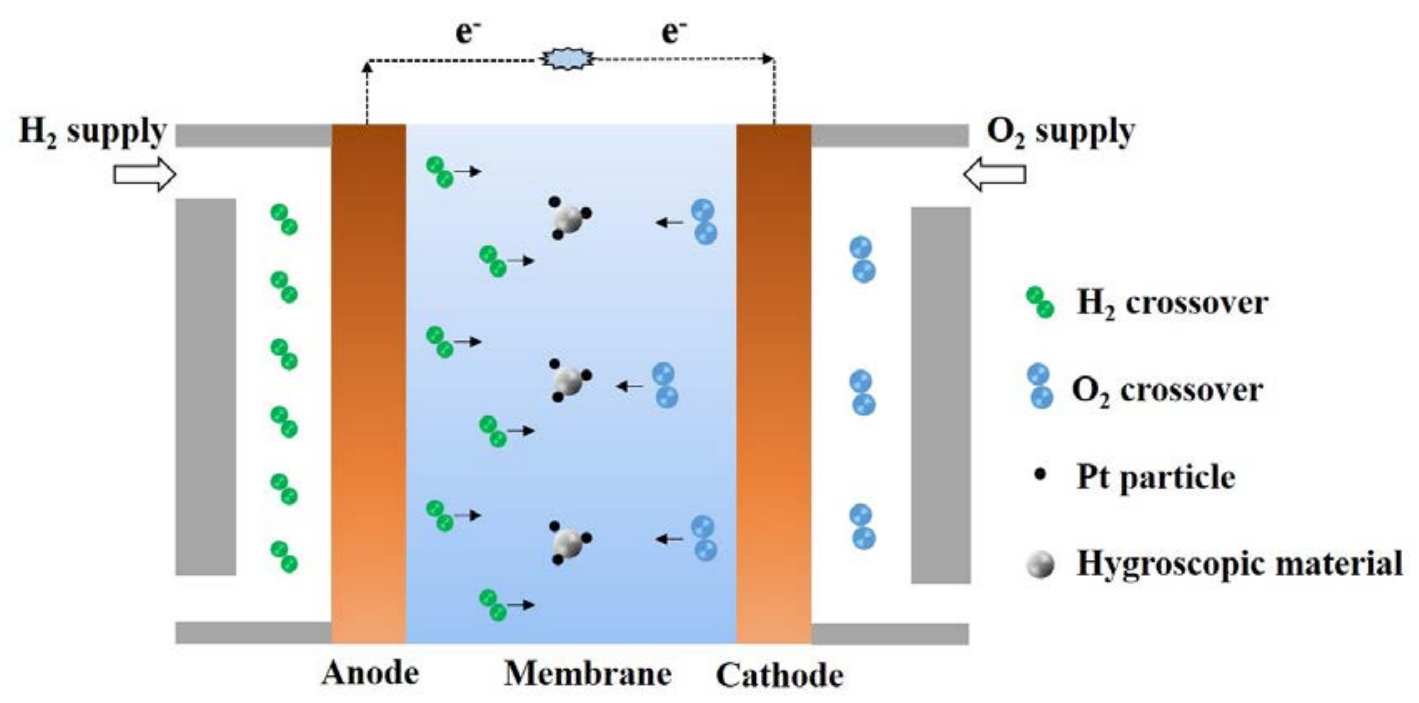

Fig. 7. Schematic of internal humidification by adding catalyst and hygroscopic material to the membrane. 


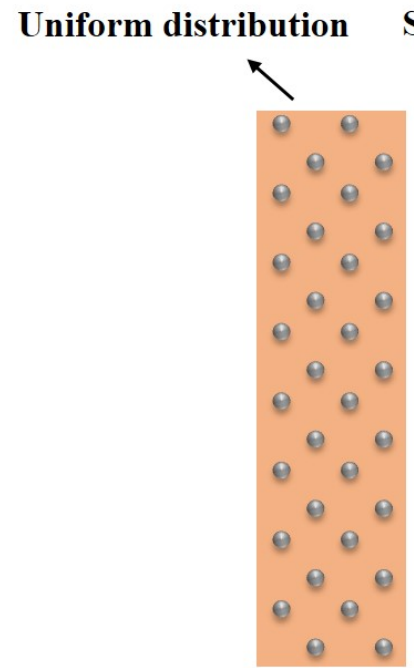

(a)

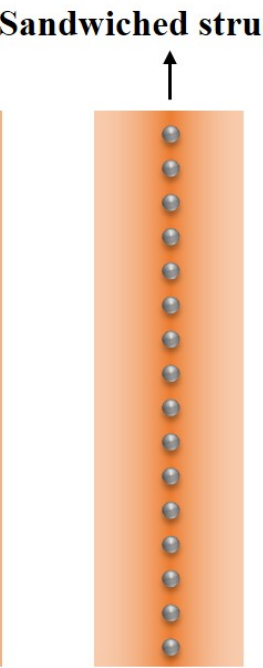

(b)

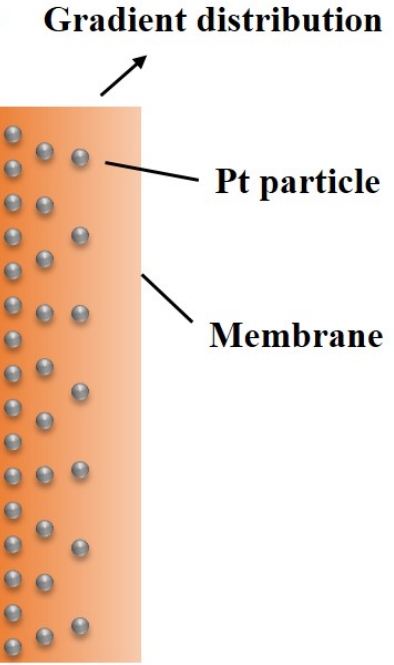

(c)

Fig. 8. Different concept of Pt distribution in the membrane [33]. 


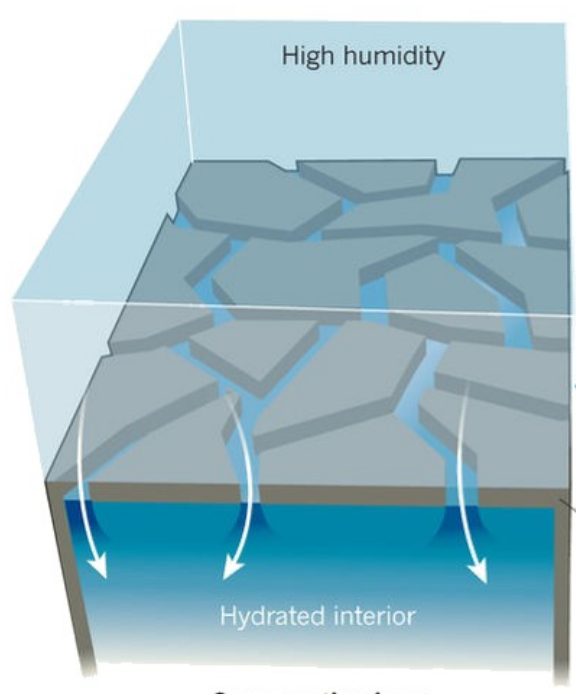

Open coating layer

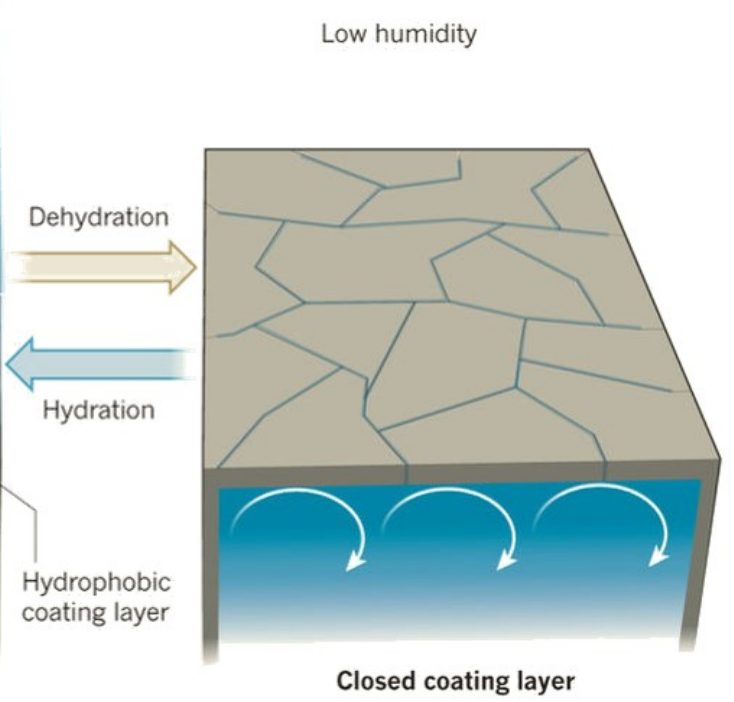

Closed coating layer

Fig. 9. The response of the membrane coating layer at both high and low humidity [51]. 

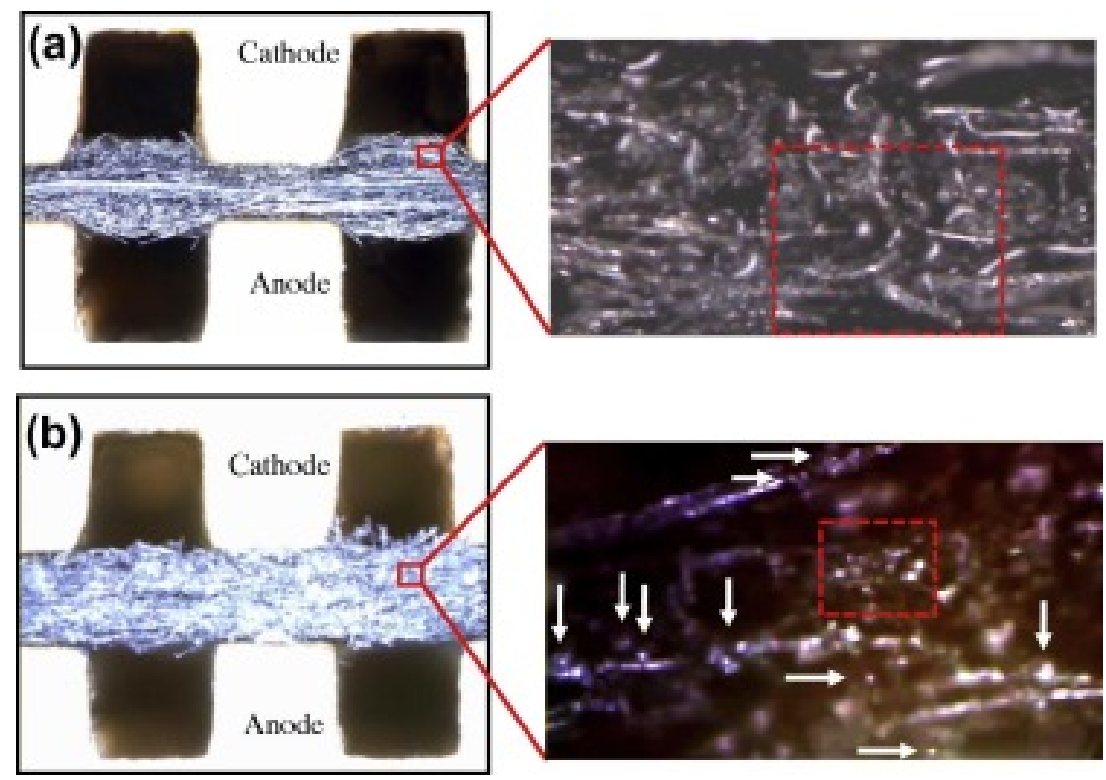

Fig. 10. Microscopy images of the condensed water at gas diffusion layer (GDL) surfaces. The properties of the two GDL samples are: (a) mean pore diameter $35 \mu \mathrm{m}$, PTFE loading $0 \%$, contact angle $80^{\circ}$; (b) mean pore diameter $25 \mu \mathrm{m}$, PTFE loading $5 \%$, contact angle $130^{\circ}[64]$. 


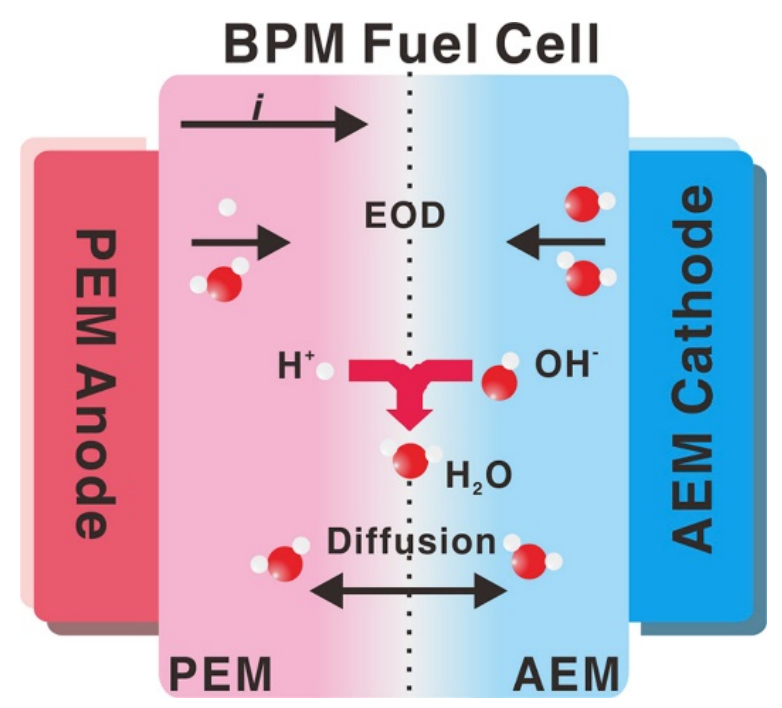

Fig. 11. Schematic of a fuel cell with "bipolar membrane" (BPM). The water production and transport mechanism are given [69]. 


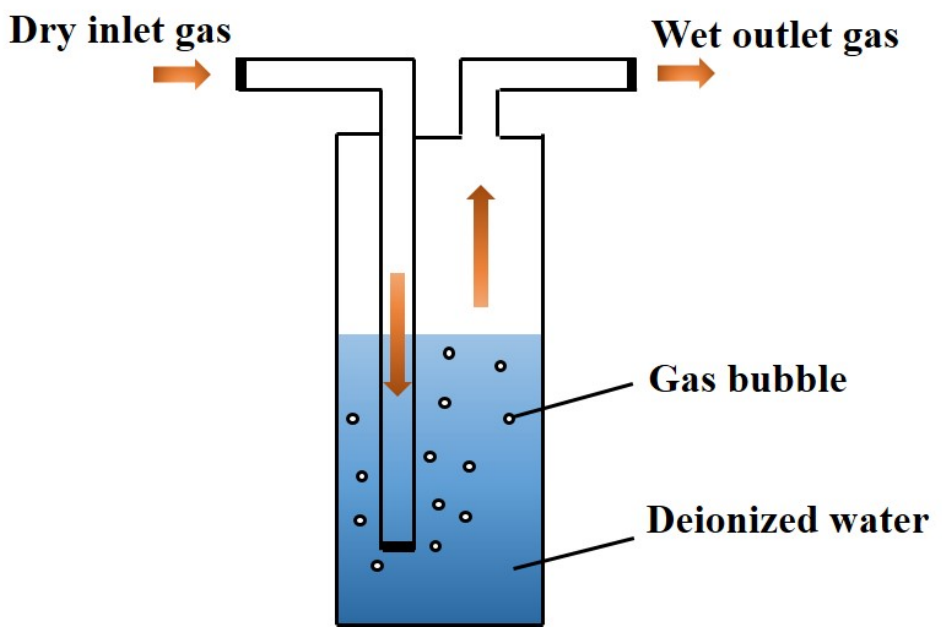

Fig. 12. Schematic of a gas bubbling humidifier. 


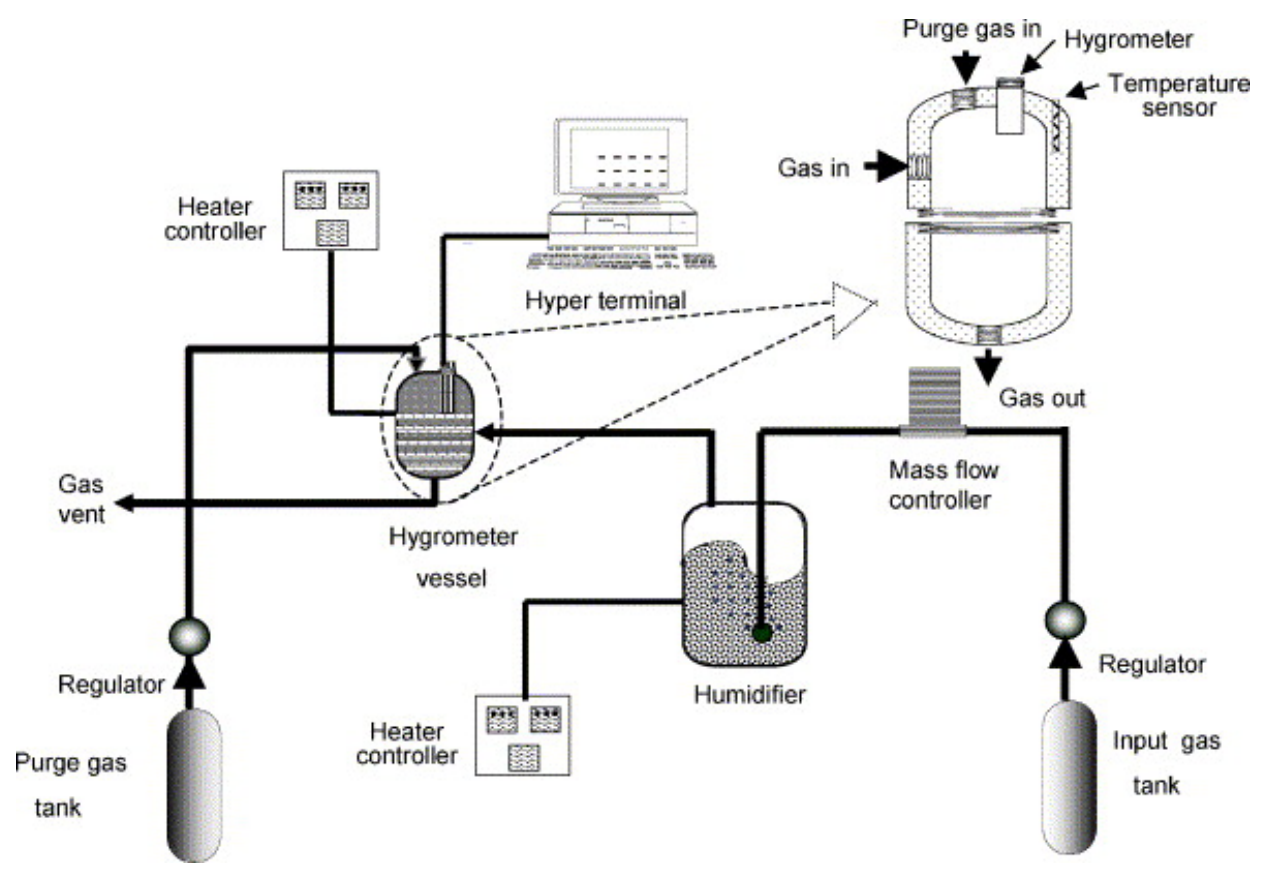

Fig. 13. Humidity measurement system used in [71]. 


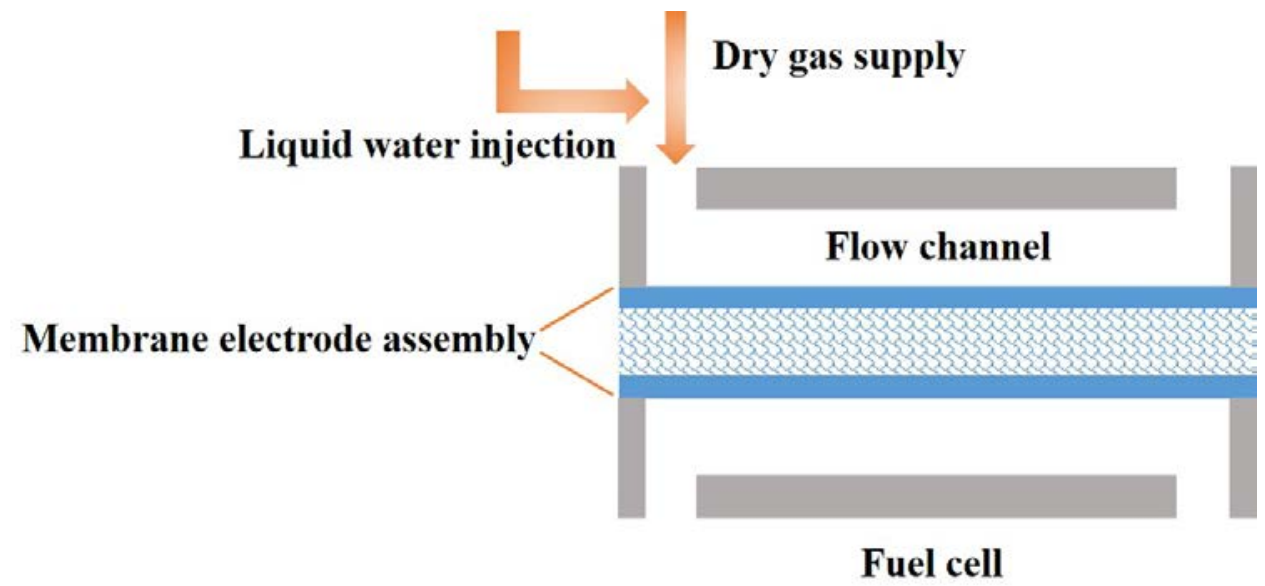

Fig. 14. Schematic of the liquid water injection method. 


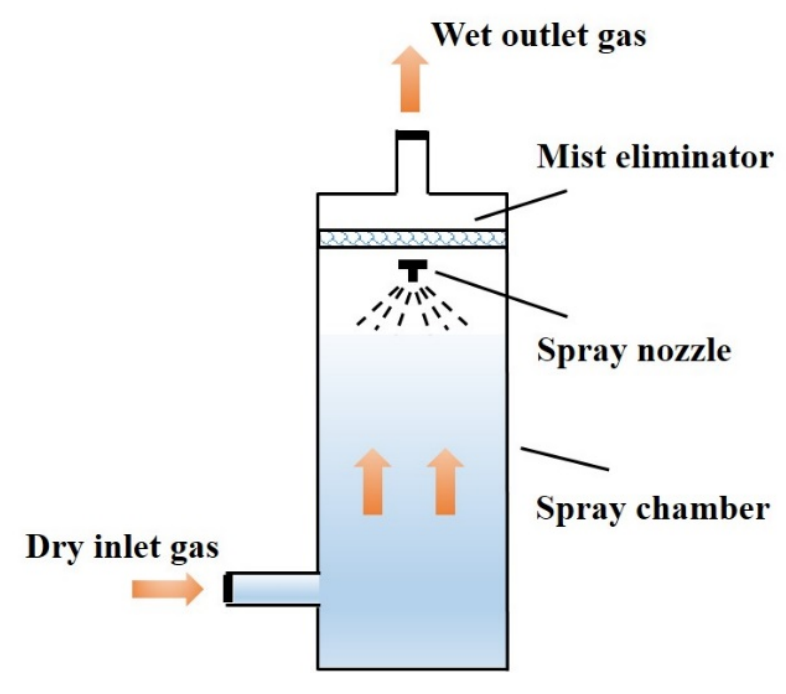

Fig. 15. Schematic of the nozzle spray humidifier. 


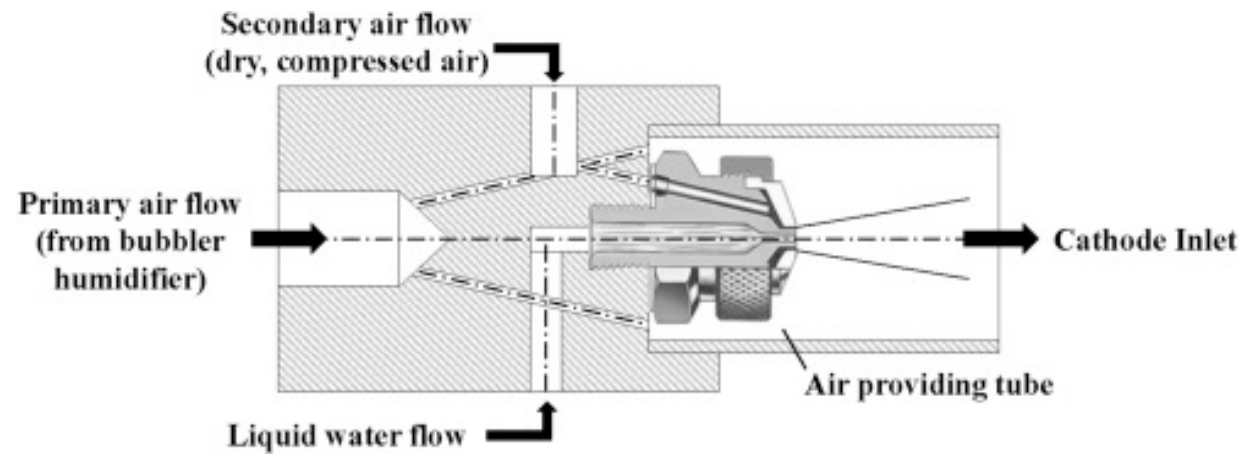

Fig. 16. Atomizer and air providing tube at the inlet of fuel cell cathode [85]. 


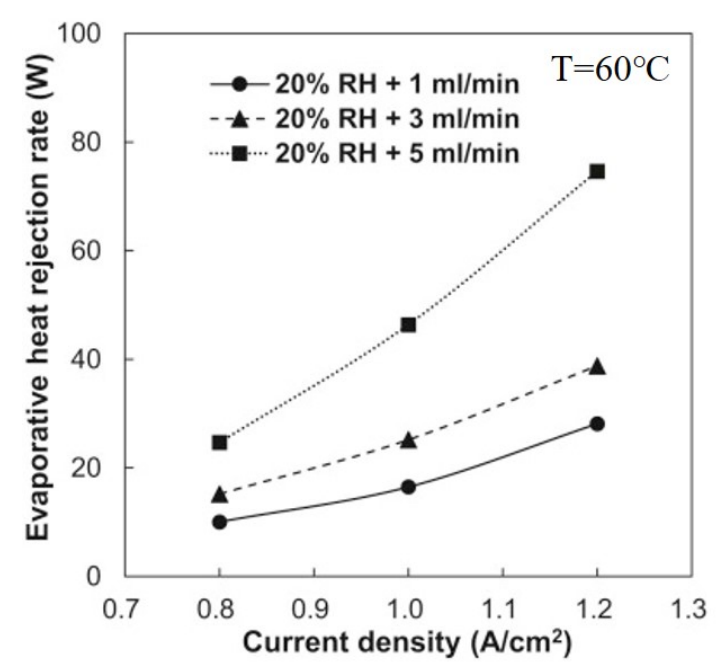

(a)

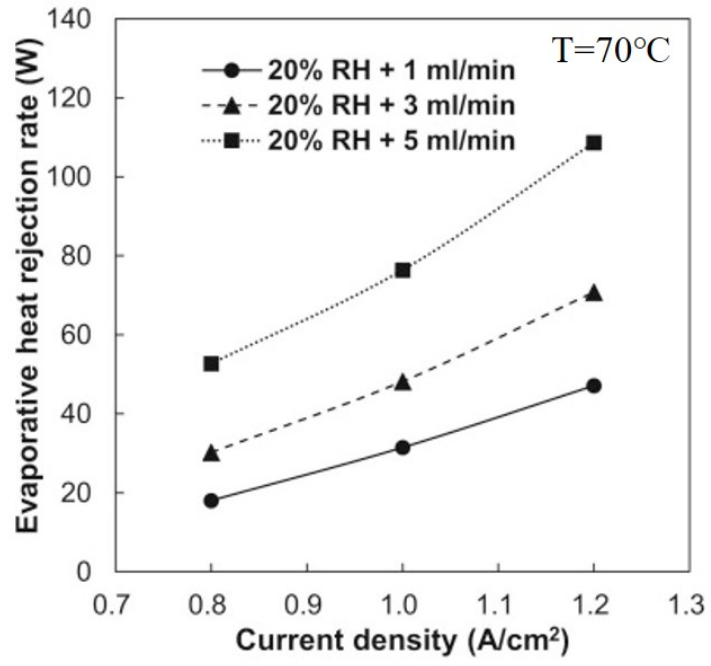

(b)

Fig. 17. Evaporative heat rejection rate caused by the liquid water cooling effect at different water injection flow rates with operating temperature of (a) $60{ }^{\circ} \mathrm{C}$ and (b) $70{ }^{\circ} \mathrm{C}[85]$. 


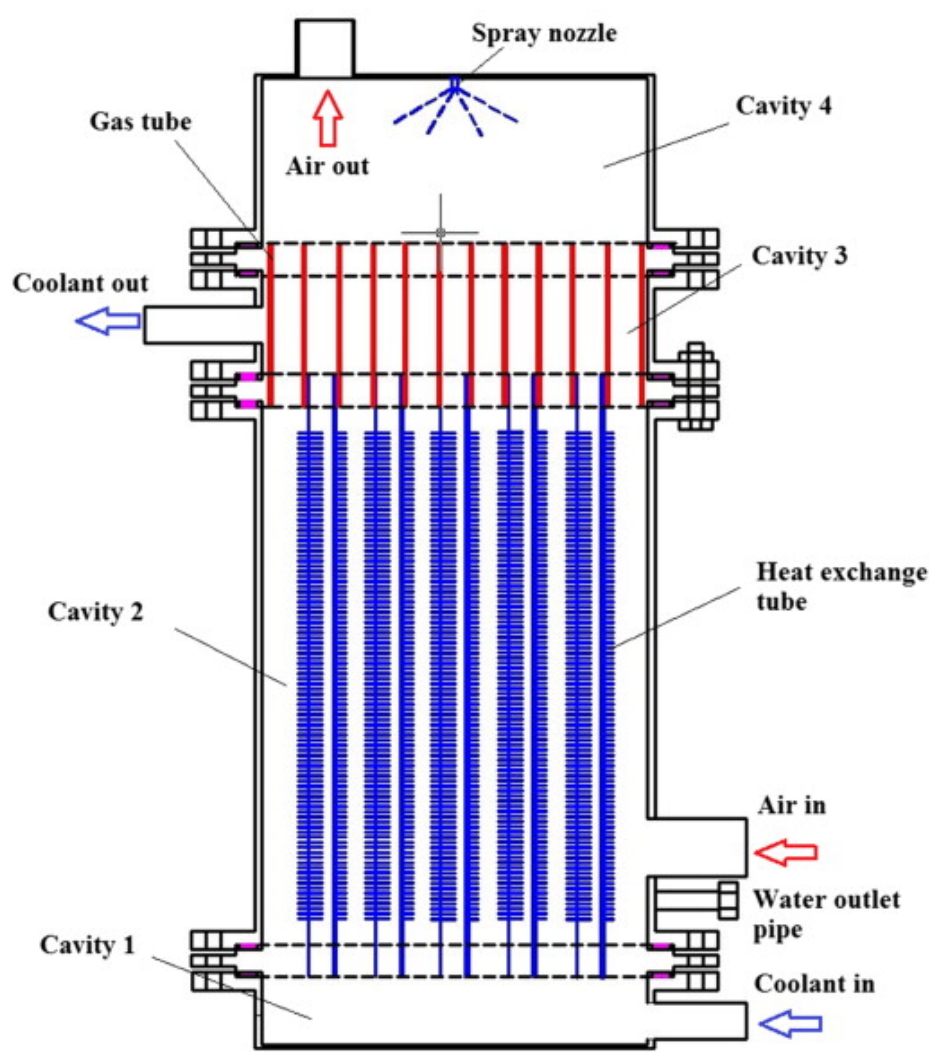

Fig. 18. Schematic of an air humidifier used for a $5 \mathrm{~kW}$ PEMFC stack [82]. 


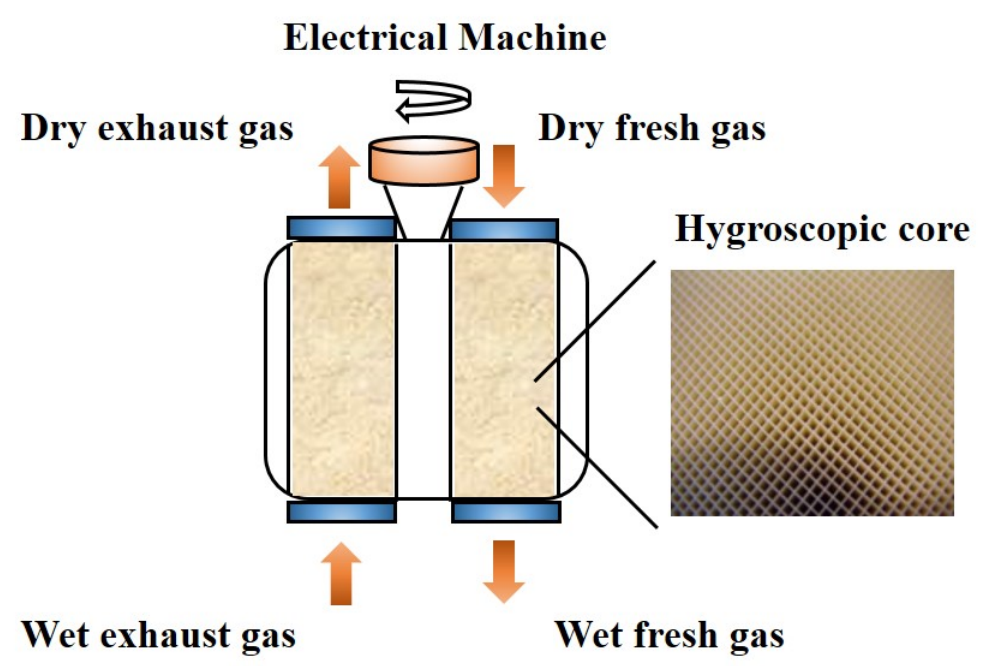

Fig. 19. Schematic of an enthalpy wheel humidifier. The hygroscopic core shown in the figure is obtained from [89]. 


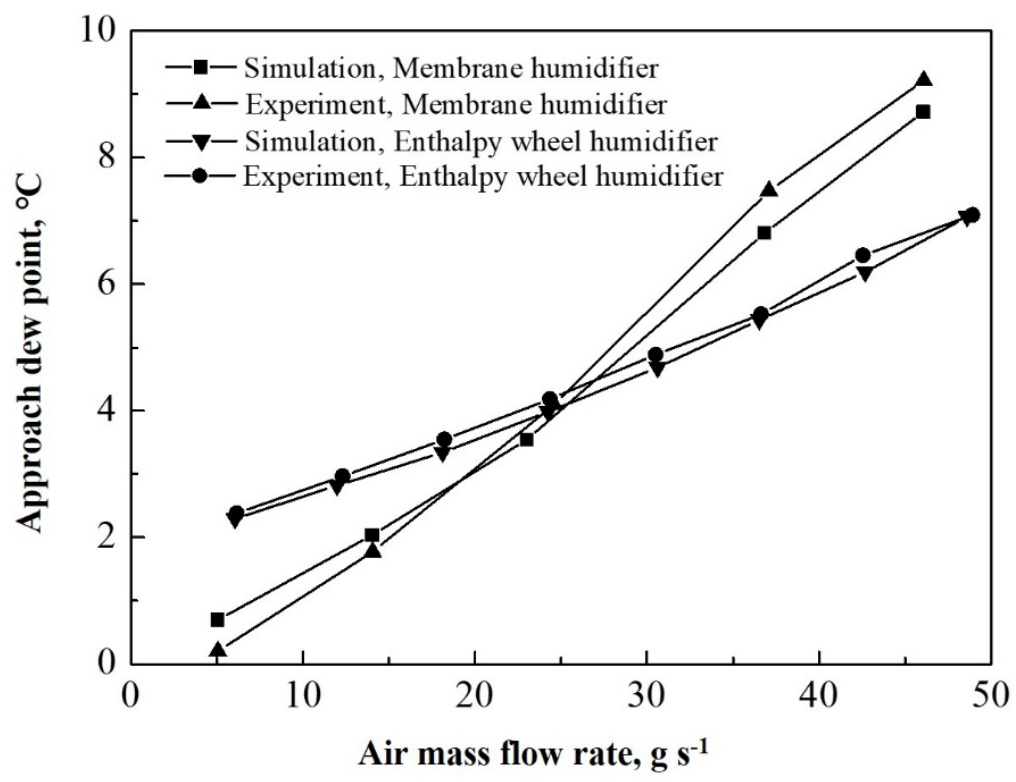

Fig. 20. Effect of mass flow rate on the performance of membrane humidifier and enthalpy wheel humidifier [90]. 


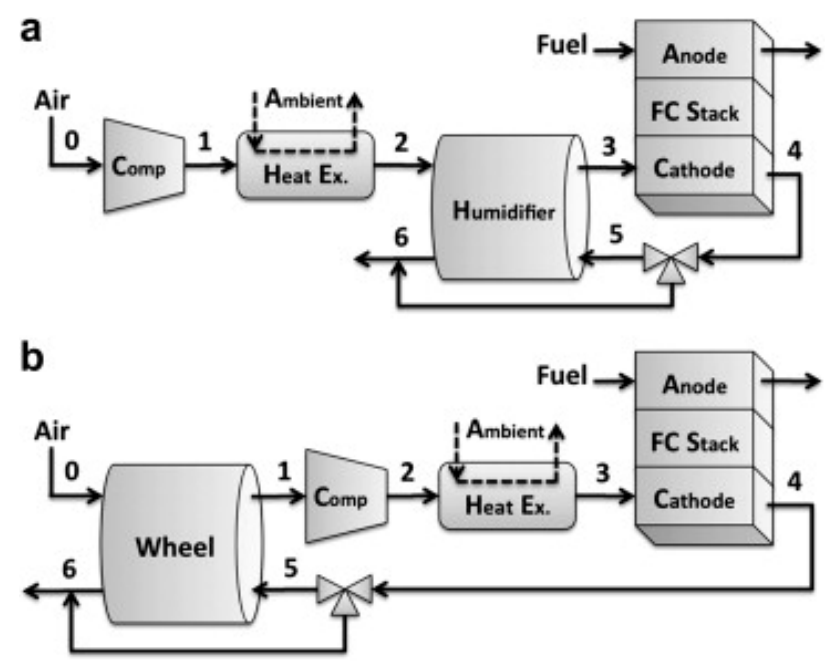

Fig. 21. PEMFC system scheme of a conventional configuration (a) and a new configuration based on enthalpy wheel humidifier (b) to reduce the pressure difference between the two flows [88]. 


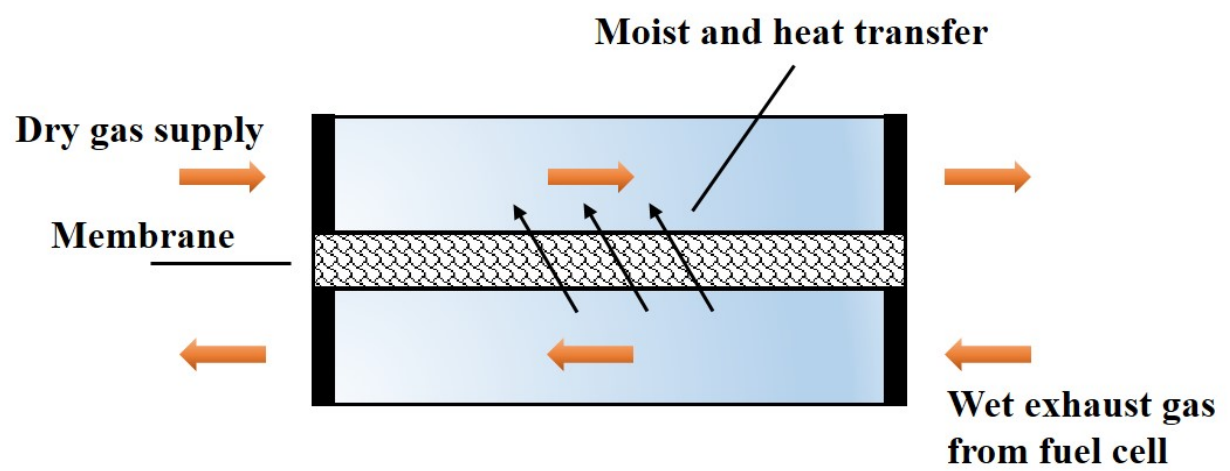

Fig. 22. Schematic of gas-to-gas membrane humidifier. 

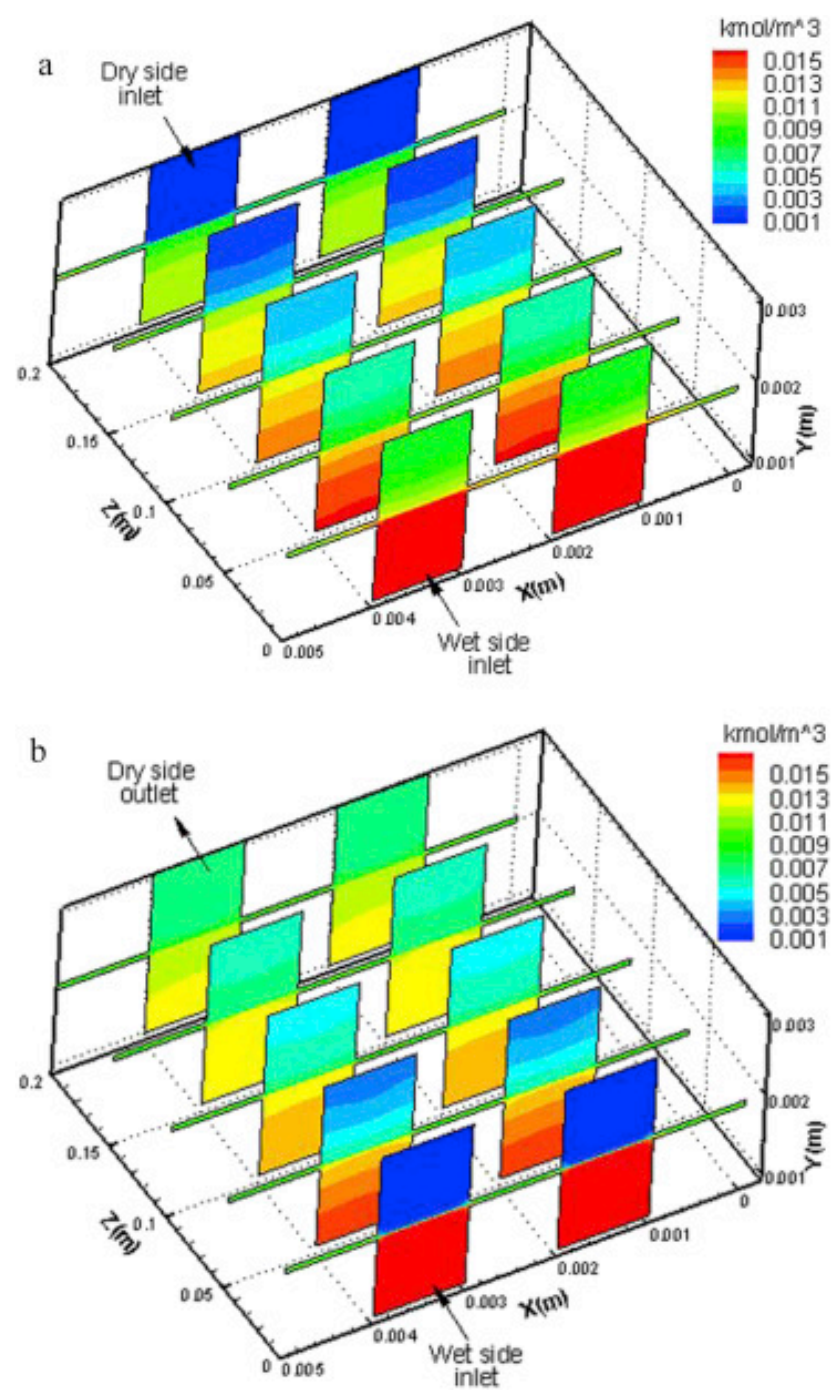

Fig. 23. Water vapor concentration distribution in the humidifier with (a) counter flow configuration and (b) parallel flow configuration [100]. 


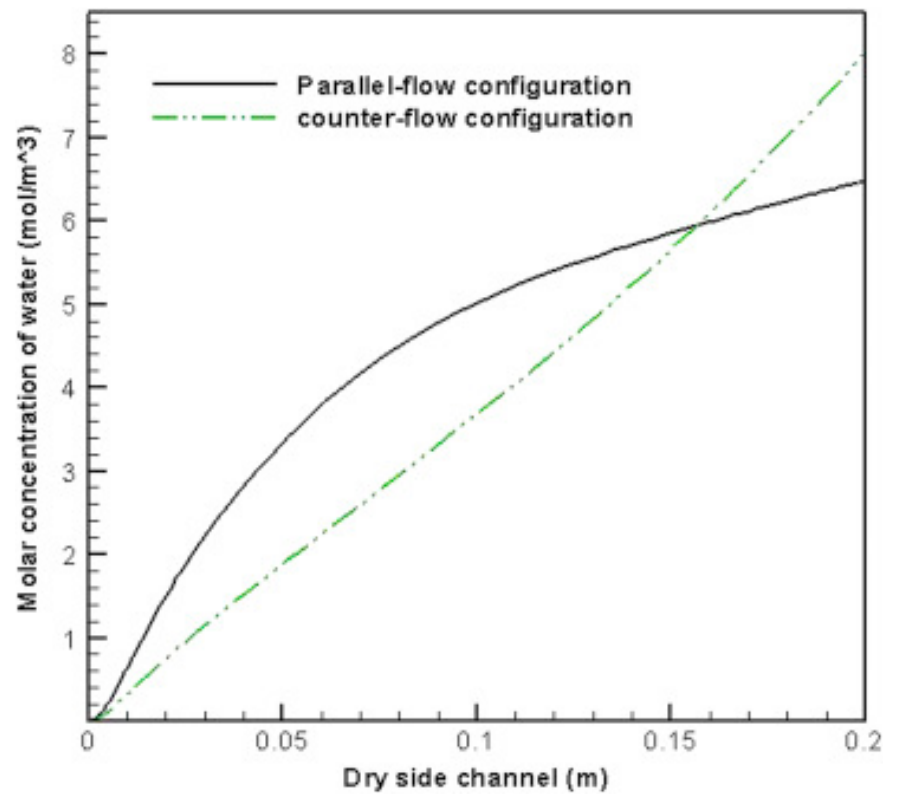

Fig. 24. Molar concentration of water vapor along the flow channel for counter flow configuration and parallel flow configuration [100]. 


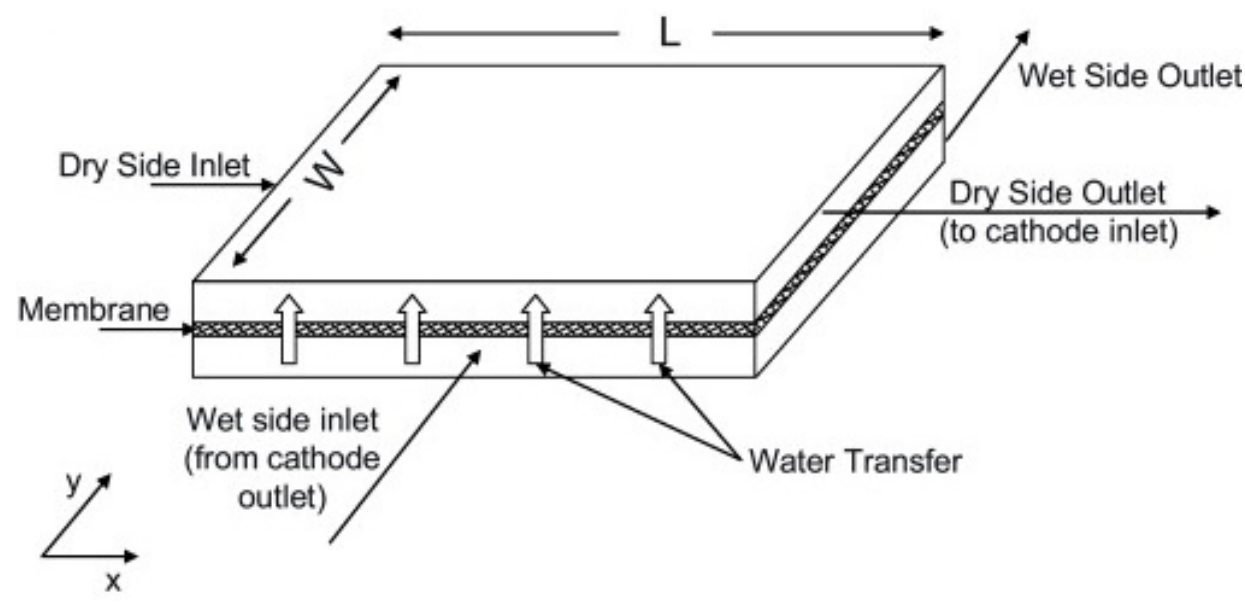

Fig. 25. Schematic of the cross flow humidifier used in [94]. 


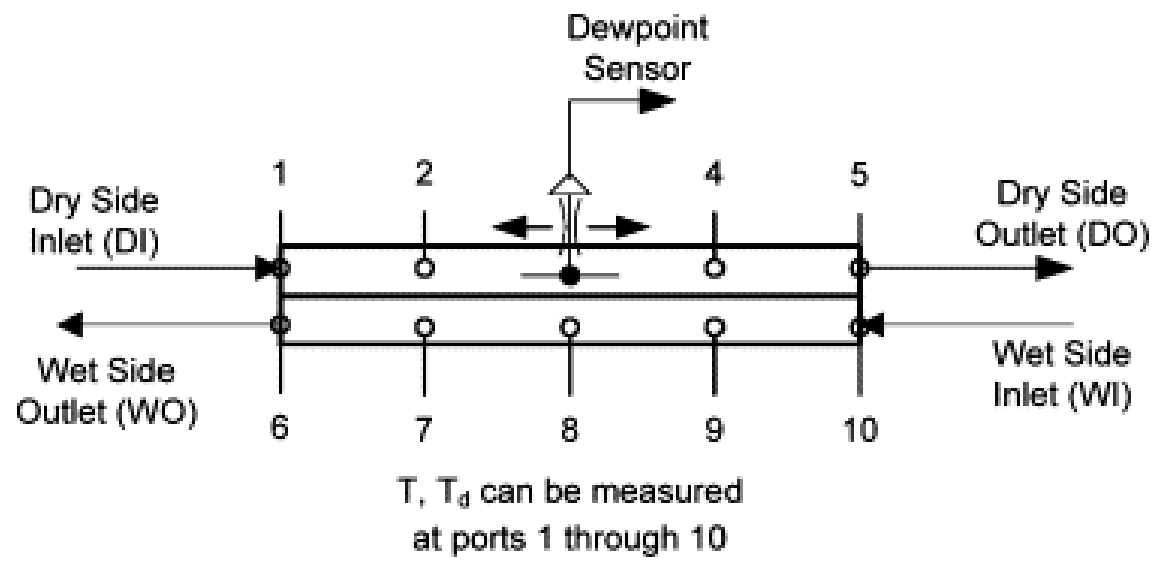

Fig. 26. Distribution of dew point sensor along the humidifier channel [93]. 


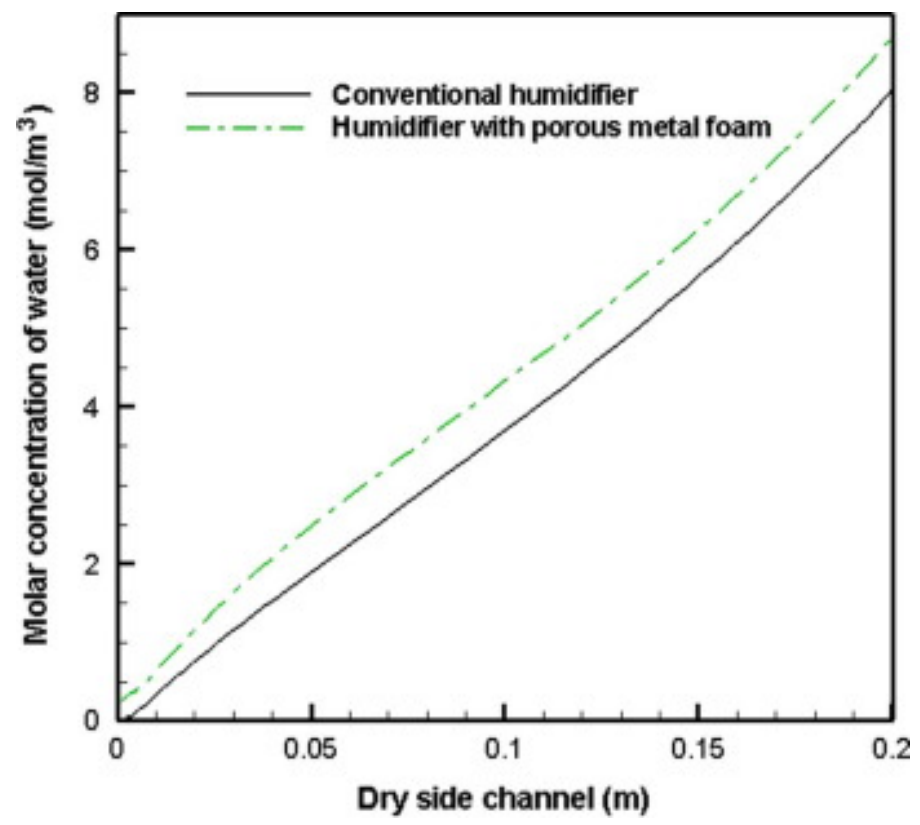

Fig. 27. Molar concentration of water vapor along the flow channel in conventional membrane humidifier and humidifier with metal foam [108]. 


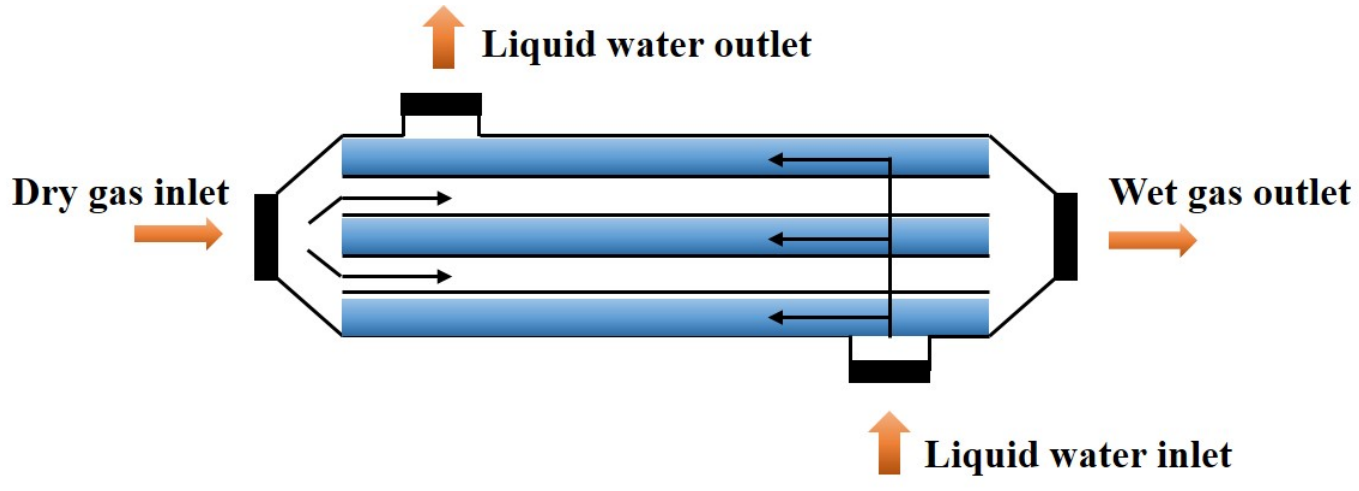

Fig. 28. Schematic of liquid-to-gas membrane humidifier. 


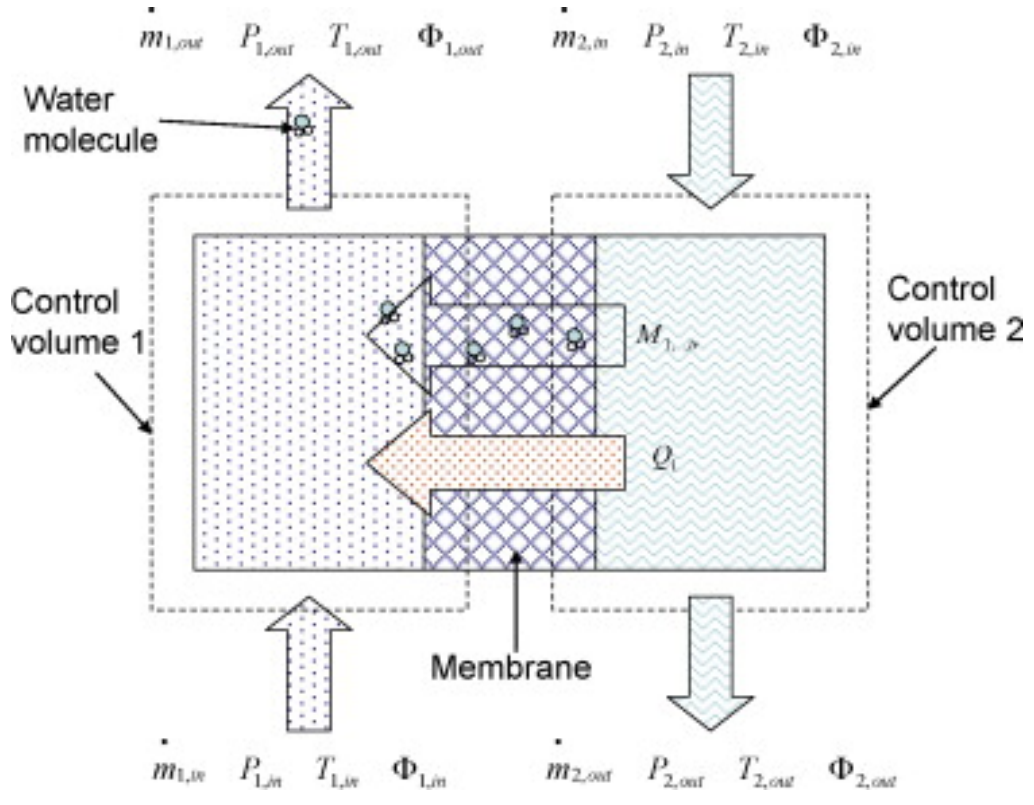

Fig. 29. Control volumes that used for a thermodynamic model [110]. 


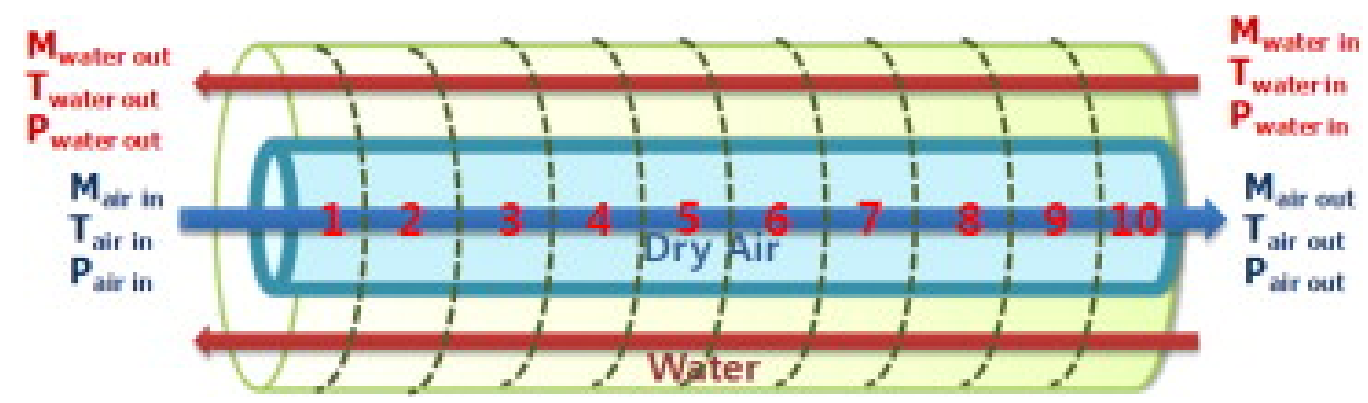

Fig. 30. Control volumes along the flow channel of the $1 \mathrm{D}+1 \mathrm{D}$ liquid-to-gas membrane humidifier model [113]. 


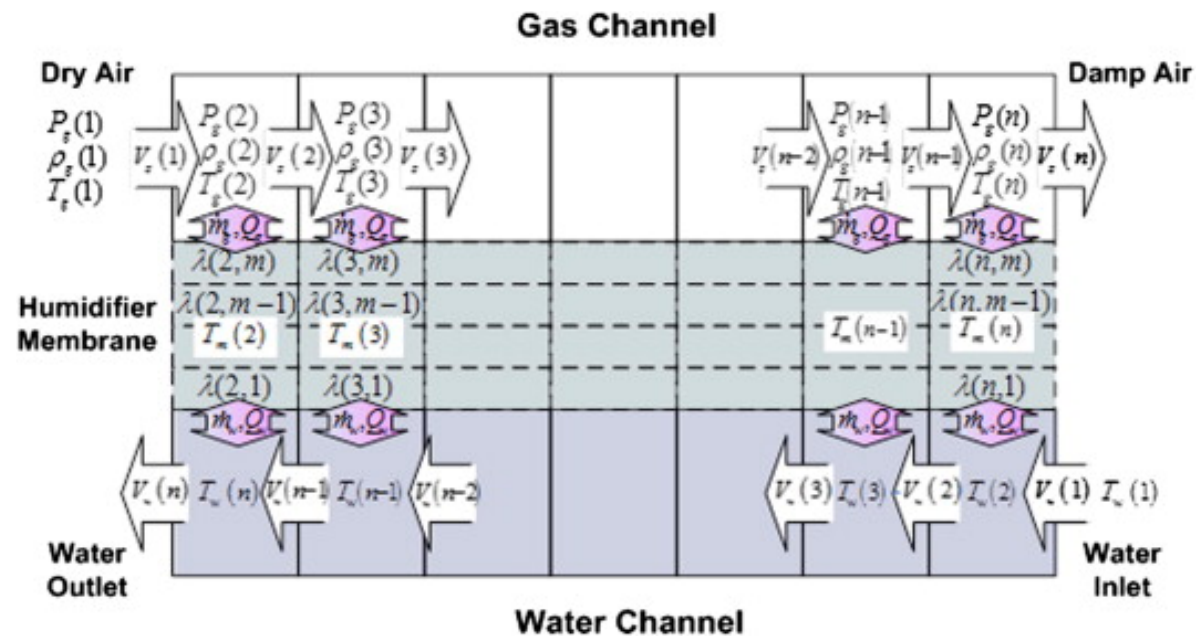

Fig. 31. Control volumes along the flow channel and the membrane as described in [115]. 


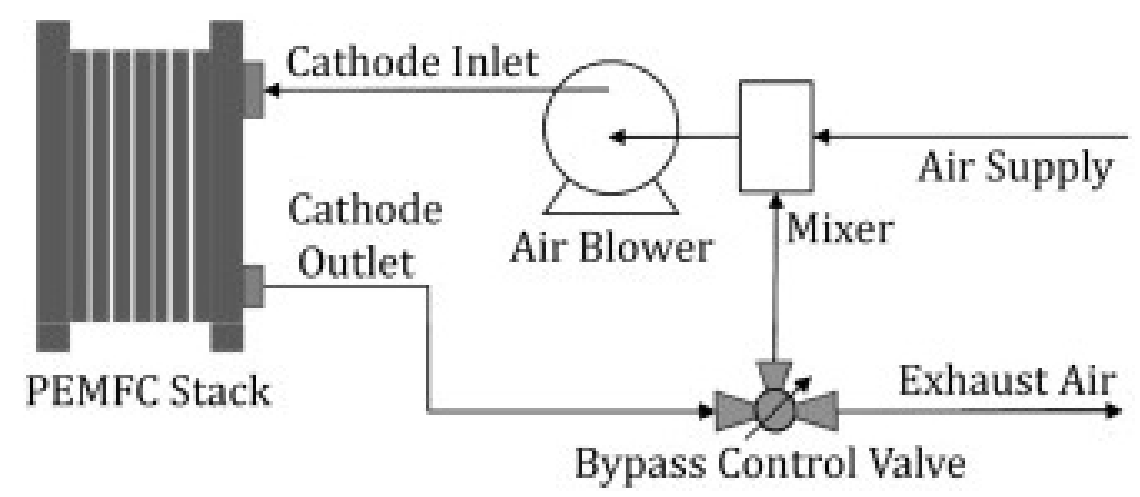

Fig. 32. Gas recirculation system being adopted in [117]. 


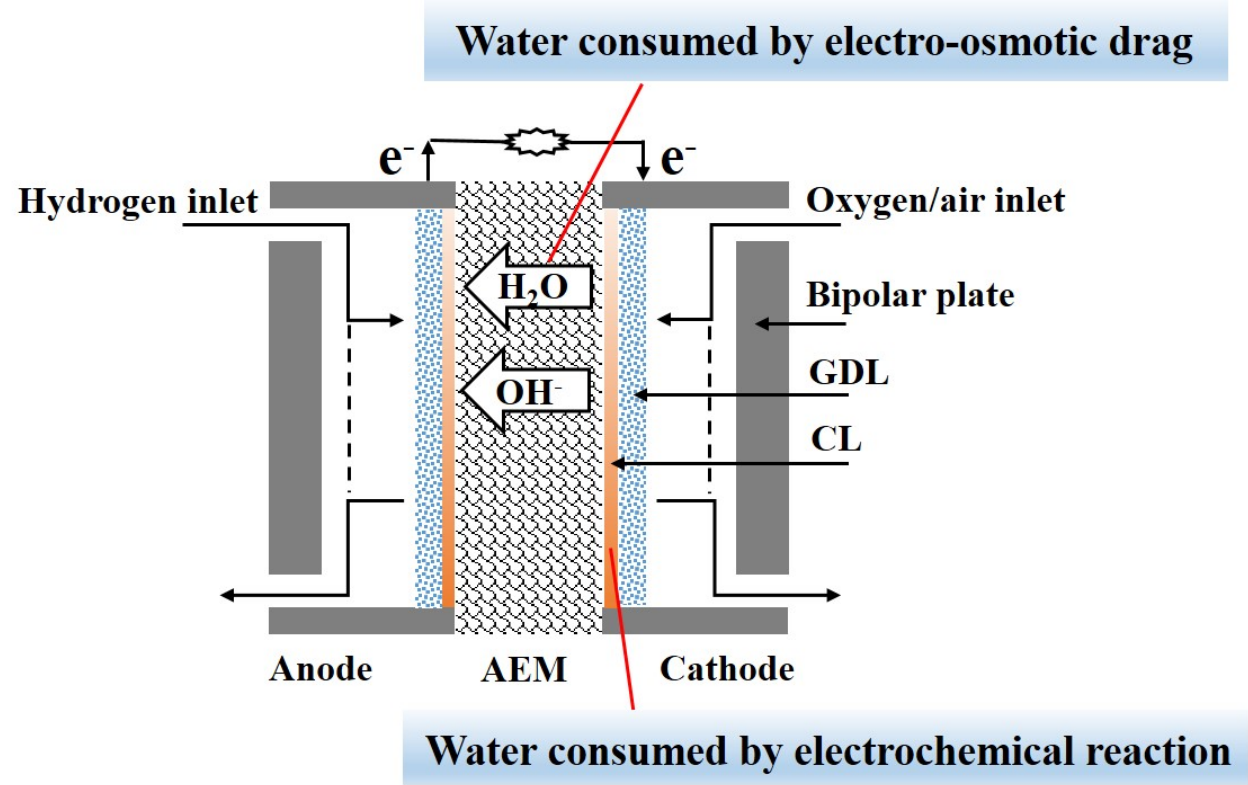

Fig. 33. Schematic of alkaline anion exchange membrane fuel cells (AEMFCs). 


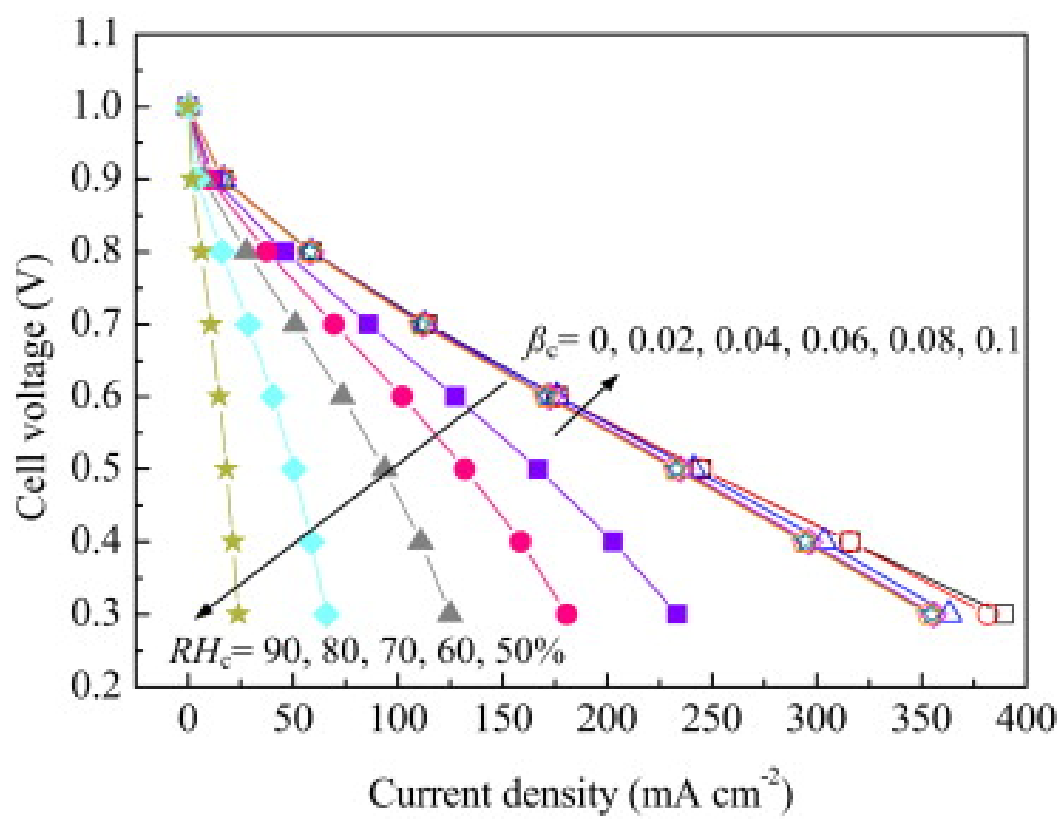

Fig. 34. Polarization curves of an AEMFC with different cathode inlet relative humidity and different amount of liquid water (volume fraction) [124]. 
Table 1 Different additives in membrane and the corresponding advantages.

\begin{tabular}{|c|c|c|}
\hline Additives & Advantages & $\begin{array}{l}\begin{array}{l}\text { Publication year and } \\
\text { references }\end{array} \\
\end{array}$ \\
\hline $\mathrm{Pt}$ & N/A & $\begin{array}{l}1998 \text { [26], } 2002 \text { [30], } \\
2003 \text { [29], } 2005 \text { [33] }\end{array}$ \\
\hline $\mathrm{Pt} / \mathrm{C}$ & N/A & 2003 [31], 2005 [32] \\
\hline $\mathrm{Pt} / \mathrm{TiO}_{2}$ & Water retention & 1996 [26], 1998 [27] \\
\hline $\mathrm{Pt} / \mathrm{SiO}_{2}$ & Water retention & $\begin{array}{l}1996 \text { [26], } 2006 \text { [34], } \\
2007 \text { [35] }\end{array}$ \\
\hline Pt/sulfated zirconia & High conductivity & $2007[36]$ \\
\hline Pt/zeolite & Hydrophilic property & 2007 [37] \\
\hline $\mathrm{Cs}_{2.5} \mathrm{H}_{0.5} \mathrm{PWO}_{40} / \mathrm{SiO}_{2}$ & $\begin{array}{l}\text { Low cost; high } \\
\text { conductivity }\end{array}$ & 2007 [38] \\
\hline $\mathrm{Pt} / \mathrm{CNTs}$ & $\begin{array}{l}\text { High membrane } \\
\text { mechanical strength }\end{array}$ & 2007 [39] \\
\hline $\mathrm{SiO}_{2} /$ sulfated zirconia & High conductivity & $2008[40]$ \\
\hline Pt/PDDA & $\begin{array}{l}\text { Simple and easy to } \\
\text { process }\end{array}$ & $2009[41]$ \\
\hline $\mathrm{Pt} / \mathrm{Cs}_{2.5} \mathrm{H}_{0.5} \mathrm{PWO}_{40}$ & High conductivity & $2011[42]$ \\
\hline $\mathrm{P}_{2} \mathrm{O}_{5}-\mathrm{SiO}_{2}$, [EMIMBF4] & $\begin{array}{l}\text { Thermal stability; } \\
\text { excellent processing } \\
\text { versatility }\end{array}$ & $2011[43]$ \\
\hline PWA/graphene & $\begin{array}{l}\text { Improvement of water } \\
\text { retention and proton } \\
\text { conductivity }\end{array}$ & $2014[44]$ \\
\hline Pt-graphene/SiO 2 & $\begin{array}{l}\text { Large surface area; high } \\
\text { mechanical strength; high } \\
\text { conductivity. }\end{array}$ & 2015 [45] \\
\hline
\end{tabular}


Table 2 Different additives in CL and the corresponding advantages.

\begin{tabular}{|c|c|c|}
\hline Supporters & Advantages & $\begin{array}{l}\text { Publication year and } \\
\text { references }\end{array}$ \\
\hline $\mathrm{SiO}_{2}$ & Water retention & $\begin{array}{l}2007 \text { [37], } 2007 \text { [53], } \\
2008 \text { [52], }\end{array}$ \\
\hline $\begin{array}{l}\text { Citric acid modified } \\
\text { carbon black }\end{array}$ & Simple and effective & $2010[54]$ \\
\hline $\mathrm{SiO}_{2} / \mathrm{C}$ & High durability & $\begin{array}{l}2010 \text { [49], } 2015 \text { [55], } \\
2015 \text { [56] }\end{array}$ \\
\hline $\begin{array}{l}\text { Sulfonated carbon } \\
\text { nanofiber }\end{array}$ & $\begin{array}{l}\text { Good compatibility with } \\
\text { Nafion; high ion-exchange } \\
\text { capacity etc. }\end{array}$ & $2011[57]$ \\
\hline polyvinyl alcohol (PVA) & $\begin{array}{l}\text { Good stability; high } \\
\text { performance }\end{array}$ & 2012 [58] \\
\hline Silica aerogel & $\begin{array}{l}\text { High water uptake and } \\
\text { proton conductivity }\end{array}$ & 2012 [59] \\
\hline $\mathrm{SiO}_{2}-\mathrm{RuO}_{2}$ & $\begin{array}{l}\text { High performance; high } \\
\text { durability }\end{array}$ & 2012 [48] \\
\hline Microcrystalline cellulose & $\begin{array}{l}\text { High performance at low } \\
\text { relative humidity; good } \\
\text { stability }\end{array}$ & 2014 [60] \\
\hline $\mathrm{HZrO}_{2}$ & $\begin{array}{l}\text { High surface area and } \\
\text { water uptake }\end{array}$ & 2017 [61] \\
\hline Pt-C/Pt-TiO 2 dual catalyst & $\begin{array}{l}\text { Good water production and } \\
\text { retention ability }\end{array}$ & 2017 [62] \\
\hline
\end{tabular}


Table 3 Design and operating parameters and their influence on the performance of gas-to-gas membrane humidifier.

\begin{tabular}{|c|c|c|c|c|}
\hline Parameters & $\begin{array}{l}\text { Water } \\
\text { recovery ratio }\end{array}$ & $\begin{array}{l}\text { Water } \\
\text { transfer rate }\end{array}$ & $\begin{array}{l}\text { Dry side } \\
\text { outlet RH }\end{array}$ & $\begin{array}{l}\text { Dry side outlet dew } \\
\text { point }\end{array}$ \\
\hline $\begin{array}{l}\text { Dry side inlet flow } \\
\text { rate }\end{array}$ & + & + & - & - \\
\hline $\begin{array}{l}\text { Dry side inlet } \\
\text { temperature }\end{array}$ & + & Negligible & - & + \\
\hline $\begin{array}{l}\text { Dry side inlet } \\
\text { pressure }\end{array}$ & - & - & + & Negligible \\
\hline Wet side flow rate & - & + & + & + \\
\hline $\begin{array}{l}\text { Wet side inlet } \\
\text { pressure }\end{array}$ & + & + & + & Negligible \\
\hline $\begin{array}{l}\text { Wet side inlet } \\
\text { temperature }\end{array}$ & N/A & - & - & N/A \\
\hline References & [93-95,107] & {$[94,95,101]$} & {$[94,95,100]$} & {$[93-95,100-102,108]$} \\
\hline
\end{tabular}


Table 4 Comparison between the conventional membrane humidifier and the humidifier with metal foam [108].

\begin{tabular}{llll}
\hline Parameters & $\begin{array}{l}\text { Water molar } \\
\text { concentration } \\
\text { dry side outlet }\end{array}$ & $\begin{array}{l}\text { Temperature at dry } \\
\text { side outlet }\end{array}$ & $\begin{array}{l}\text { Dew point at dry } \\
\text { side outlet }\end{array}$ \\
\hline $\begin{array}{l}\text { Unit } \\
\begin{array}{l}\text { Conventional } \\
\text { humidifier }\end{array}\end{array}$ & 8.41 & $\mathrm{~K}$ & $\mathrm{~K}$ \\
$\begin{array}{l}\text { Humidifier that } \\
\text { containing porous } \\
\text { metal foam on }\end{array}$ & 8.97 & 345.81 & 337.62 \\
both sides & & 347.5 & 339.12 \\
\hline
\end{tabular}


Table 5 Operating parameters and their influence on the performance of liquid-to-gas membrane humidifier.

\begin{tabular}{|c|c|c|c|}
\hline Parameters & Water transfer rate & $\begin{array}{l}\text { Dry side outlet } \\
\text { RH }\end{array}$ & $\begin{array}{l}\text { Dry side outlet } \\
\text { dew point }\end{array}$ \\
\hline Dry side inlet flow rate & + & - & - \\
\hline $\begin{array}{l}\text { Dry side inlet } \\
\text { temperature }\end{array}$ & + & - & + \\
\hline Dry side inlet pressure & - & - & - \\
\hline Water flow rate & + & Negligible & N/A \\
\hline Water channel pressure & Negligible & N/A & N/A \\
\hline Inlet water temperature & + & + & + \\
\hline References & {$[110,113,115]$} & {$[115,116]$} & {$[113,115]$} \\
\hline
\end{tabular}




\section{Highlights}

Reviewed methods for the humidification of polymer electrolyte membrane fuel cells.

Categorized into internal and external humidification methods.

Presented advantage and drawback of each humidification method.

Summarized suitable applications for each humidification method. 